\title{
STRESS, MOOD, EATING, AND CRAVING
}

by

\author{
Ashley Charbonneau
}

\begin{abstract}
A thesis submitted to
the Faculty of Graduate and Postdoctoral Affairs

in partial fulfillment of the requirements for the degree of

Master of Science

in

Psychology
\end{abstract}

\section{Carleton University \\ Ottawa, Canada}

C2010 Ashley Charbonneau 
Library and Archives

Canada

Published Heritage

Branch

395 Wellington Street

Ottawa ON K1A ON4

Canada
Bibliothèque et

Archives Canada

Direction du

Patrimoine de l'édition

395, rue Wellington

Ottawa ON K1A ON4

Canada
Your file Votre référence

ISBN: 978-0-494-71575-8

Our file Notre référence

ISBN: 978-0-494-71575-8
NOTICE:

The author has granted a nonexclusive license allowing Library and Archives Canada to reproduce, publish, archive, preserve, conserve, communicate to the public by telecommunication or on the Internet, loan, distribute and sell theses worldwide, for commercial or noncommercial purposes, in microform, paper, electronic and/or any other formats.

The author retains copyright ownership and moral rights in this thesis. Neither the thesis nor substantial extracts from it may be printed or otherwise reproduced without the author's permission.
AVIS:

L'auteur a accordé une licence non exclusive permettant à la Bibliothèque et Archives Canada de reproduire, publier, archiver, sauvegarder, conserver, transmettre au public par télécommunication ou par l'Internet, prêter, distribuer et vendre des thèses partout dans le monde, à des fins commerciales ou autres, sur support microforme, papier, électronique et/ou autres formats.

L'auteur conserve la propriété du droit d'auteur et des droits moraux qui protège cette thèse. $\mathrm{Ni}$ la thèse ni des extraits substantiels de celle-ci ne doivent être imprimés ou autrement reproduits sans son autorisation.
In compliance with the Canadian Privacy Act some supporting forms may have been removed from this thesis.

While these forms may be included in the document page count, their removal does not represent any loss of content from the thesis.
Conformément à la loi canadienne sur la protection de la vie privée, quelques formulaires secondaires ont été enlevés de cette thèse.

Bien que ces formulaires aient inclus dans la pagination, il n'y aura aucun contenu manquant.

\section{Canadä}




\begin{abstract}
Stressful events can have profound effects on physical and psychological wellbeing and their impact can vary depending on the type of stressor encountered, emotional and physiological responses, and individual characteristics. The present investigation examined the effects of emotional eating and depressive symptomatology (typical and atypical) on responses to the anticipation of performing a speech and mental math task in front of a panel of judges. Measurements were taken of mood, food craving, and salivary cortisol. Emotional eating was associated with significantly greater levels of shame and food cravings, irrespective of stressor condition. Specific food cravings were evident for sugar and carbohydrates, and were mediated by anticipation of relief, followed subsequently by anticipation of positive reinforcement. Although emotional eating was not related to cortisol reactivity, typical depressive symptomatology (and not atypical) was related to a significant increase of cortisol in response to the stressor. The implication of these findings is discussed.
\end{abstract}




\section{Acknowledgements}

I would like to express my sincere gratitude to Dr. Hymie Anisman for his honest feedback, encouragement, support, and guidance, and for helping me to realize my potential. I would also like to thank Dr. Alfonso Abizaid for sharing his knowledge and insight regarding this area of study, as well as Dr. Frank Elgar for his help during the analysis stage of this thesis. Thank you to Kate Raspopow for always being willing to take the time to teach me and answer any questions I had, as well as to other members of the lab. Thank you to Dr. Michèle Gagnon, for her support and guidance during all stages of this process, and for helping me to recognize my ability to succeed on my own. Finally, thank you to my parents and Jay, for their constant support and belief in me, which is what allowed me to be here and to achieve my goals. 


\section{Table of Contents}

Title $\mathrm{i}$

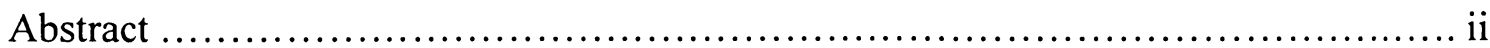

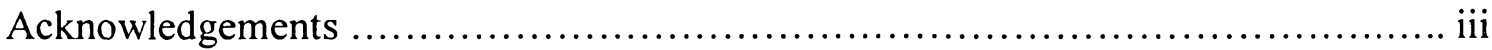

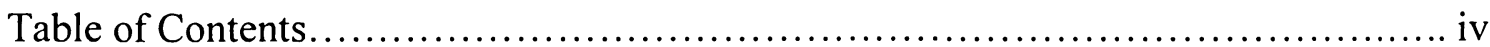

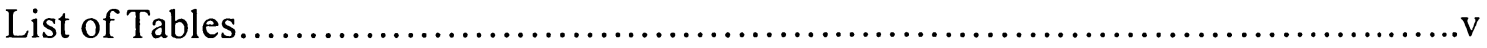

List of Figures...........................................................

List of Appendices........................................................

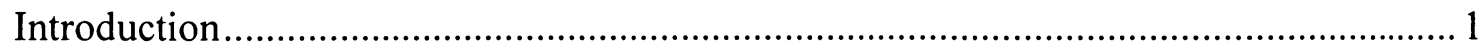

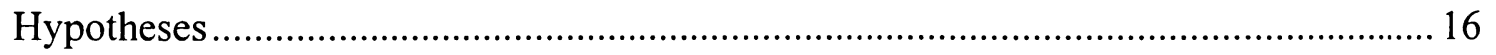

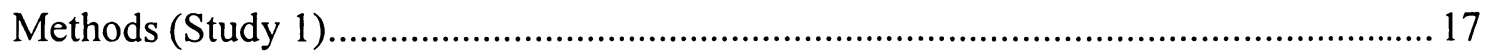

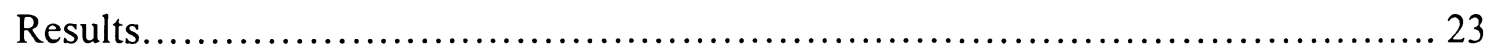

Discussion............................................................ 40

References...............................................................52

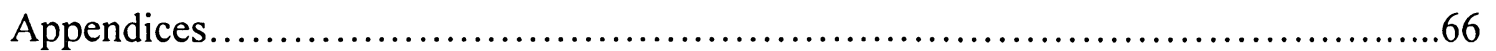




\section{List of Tables}

Table 1. Descriptive Statistics (Means, Standard Deviations, and Ranges) as a Function of Condition

Table 2. Hierarchical Regression Assessing Immediate Feelings of Anxiety as a Function of Emotional Eating Behaviours and Condition (Stressor/Control).

Table 3. Hierarchical Regression Assessing the Relation between Emotional Eating and

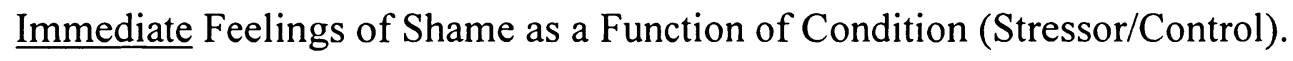

Table 4. Hierarchical Regression Assessing the Relation between Emotional Eating and Change in Feelings of Shame over time (20-min) as a Function of Condition (Stressor/Control).

Table 5. Hierarchical Regression Assessing Emotional Eating and Preference for Sweets as Predictors of Craving for Sweets immediately post-task.

Table 6. Study 1 Pearson Correlations among Emotional Eating, and General and Specific Food Cravings immediately post-task (A) and 20-minutes later (B). (Time A above the diagonal, Time $\mathrm{B}$ below the diagonal)

Table 7. Pearson Correlations among Depressive Symptomatology, Feelings of Shame (immediately post-task and difference scores between 20-minutes post-task and immediately post-task), and Cortisol reactivity (difference scores and ratio scores between 10-minutes post-task and immediately post-task).

Table 8. Hierarchical Regression Assessing the Relation between Typical Depressive Symptomatology and Cortisol Ratio scores (10-min post-task: Baseline) as a Function of Condition (Stressor/Control). 


\section{List of Figures}

Figure 1. Hierarchical Regression lines showing the moderating effect of Condition (Stressor vs. Control) on the relation between Emotional Eating and feelings of Shame for the 20-minute period post task (Shame Time B - Shame Time A).

Figure 2. Anticipation of Relief from Negative States as Result of Eating, Anticipation of Positive Reinforcement that may result from Eating, and Preoccupation with Food or Lack of Control over Eating as Multiple Mediators of the relationship between Emotional Eating and Sugar Craving Immediately Post-task (Time A).

Figure 3. Anticipation of Positive Reinforcement that may result from Eating as a Mediator between Emotional Eating and Sugar Craving 20-minutes Post-task (Time B).

Figure 4. Anticipation of Positive Reinforcement that may result from Eating, and Preoccupation with Food or Lack of Control over Eating as Multiple Mediators of the relationship between Emotional Eating and Carbohydrate Craving 20-minutes Post-task (Time B).

Figure 5. Hierarchical Regression lines showing the moderating effect of Condition (Stressor vs. Control) on the Relation between Typical Depressive Symptomatology (Total Scores on Beck Depression Inventory) and Cortisol Ratio scores (10-min posttask: Baseline). 


\section{List of Appendices}

Appendix A. Study 2 Methods and Results

Appendix B. Informed Consent

Appendix C. Background and Health Information

Appendix D. Beck Depression Inventory, with additional items

Appendix E. Positive and Negative Affect Schedule with additional adjectives

Appendix F. State Anxiety Inventory

Appendix G. Stress Appraisal Measure

Appendix H. General Food Cravings Questionnaire, State

Appendix I. Food-Craving Inventory

Appendix J. The Dutch Eating Behavior Questionnaire

Appendix K. Ruminative Response Scale

Appendix L. Debriefing 


\section{Introduction}

Considerable research has been conducted to assess the physiological and psychological responses to various types of stressors, and the subsequent consequences on individual health and well-being. The impact of stressors on physical and mental health can vary depending on the type and severity of the stressor, individual characteristics and coping styles. According to Lazarus and Folkman (1984), individuals typically attempt various coping strategies to deal with stressors, which can be broadly classified as being either problem-focused (aimed at changing the situation for the better), or emotion-focused (aimed at regulating the level of emotional distress). Chronic stressors and the inappropriate use of coping strategies (typically emotion-focused) have been associated with symptoms of anxiety and depression (Brown, Bifulco \& Harris, 1987; Wheatley, 1998; Kendler, Karkowski \& Prescott, 1999).

One form of emotion-focused coping that is commonly endorsed is that of avoidance-distraction, which involves engaging in activities or behaviours unrelated to the stressor in an effort to avoid a problem, rather than confronting the situation. For some individuals, eating constitutes an alternative (avoidant) behavior. Overeating in response to negative affect, which can be brought on by stress, is termed "emotional eating" potentially serving as a distractor or a way of making the individual feel better (i.e., a form of self-medication). Maladaptive coping strategies have, indeed, been associated with emotional eating, bingeing, dieting and disordered eating attitudes (Spoor et al., 2007; Ball \& Lee, 2002; Denisoff \& Endler, 2000; Fitzgibbon \& Kirschenbaum, 1990; Freeman \& Gil, 2004; Koff \& Sangani, 2007). Moreover, overeating in response to 
negative emotions has been found in obese individuals with and without binge eating disorder (Agras \& Telch, 1998; Eldredge, \& Agras, 1996; Van Strien, \& Ouwens, 2003), as well as in normal-weight dieters (Polivy, Herman, \& McFarlane, 1994)

Stressors generally have bidirectional relationships with food intake. Although emotional eaters overeat in response to stressors, it also appears that some individuals eat less under similar conditions. In line with the view that stressor-related eating is subserved by biological changes, it has been reported that acute stressors are associated with physiological changes which are typically associated with a reduction in eating, including activation of the hypothalamic pituitary axis, glycogenolysis (elevation of blood sugar), and slowed gastric emptying (Cannon, 1915, Carlson, 1916, as cited in van Strien, \& Ouwens, 2003; York, 1992). However, the acute stress response has also been associated with overeating. Individuals with relatively high cortisol reactivity have been found to overeat in response to cognitively demanding and ego-threatening stressors (Epel, Lapidus, McEwen, \& Brownell, 2001) as well as chronic daily hassles (Newman, O'Connor, \& Conner, 2007).

In addition to numerous other actions, stressors have been found to influence specific food cravings and food choices. In this regard, craving strength and frequency have been strongly associated with emotional and external eating, and the provocation of unplanned and overeating behaviour (Burton, Smit \& Lightowler, 2007; Hill, Weaver \& Blundell, 1991; Macht \& Mueller, 2007). Both acute and chronic stressor experiences, as well as negative affect, have been associated with increased intake of foods high in sugar, fat and carbohydrates, even in individuals who show an overall decrease in food intake in response to stressors (Fernstrom \& Kupfer, 1987; Grunberg \& Straub, 1992; Kandiah, 
Yake, \& Willett, 2008; McCann, Warnick, \& Knopp, 1990; Oliver, \& Wardle, 1999;

Pollard, Steptoe, Canaan, Davies, \& Wardle, 1995). Emotional eaters, in particular, report eating foods that are more palatable, higher in fat and sugar, and less healthy (such as chips, chocolate, and cookies) in response to specific stressors that elicit negative emotions and during general periods of stress (Wallis \& Hetherington, 2009).

The objective of the present investigation was to gain a better understanding of factors that might influence craving and overconsumption of specific foods. As considerable inter-individual variability exists in this regard, and indeed it seems that although some individuals increase their food consumption in response to stressors, others show a reduction of food consumption, it was of particular interest to establish the influence of individual difference factors (particularly emotional eating) as well as psychological factors (emotions, motivation) on stressor-related responses to food. As cortisol has been implicated in stress responses and in food consumption (Dallman, 2010), we assessed the relationship between emotional eating and cortisol changes associated with a stressor. As well, as it has been reported that stressors can provoke physiological changes that have been associated with an increased risk of depression, we investigated the relationship between depressive symptomatology (typical and atypical) and cortisol reactivity.

Stress, eating and biological factors

Cortisol response to stressors. Acute stressors activate a series of endocrine responses. Within seconds of experiencing an acute stressor, the sympathetic nervous system secretes catecholamines (epinephrine and norepinephrine) and the hypothalamic- 
pituitary-axis (HPA-axis) is activated (Sapolsky, Romero \& Munck, 2000). The HPAaxis operates through feedback interactions between the hypothalamus, pituitary glands and adrenal glands. Once triggered, the hypothalamus releases corticotrophin-releasing hormone $(\mathrm{CRH})$ into portal circulation, activating secretion of adrenocorticotropic hormone $(\mathrm{ACTH})$ by the pituitary gland, and within minutes the adrenal glands secrete glucocorticoids (corticosterone in animals, cortisol in humans) (Sapolsky et al., 2000). Under acute stress conditions, glucocorticoid feedback inhibits the further secretion of $\mathrm{CRH}$, but if a stressor is sufficiently intense or occurs chronically, a decrease in functioning of the glucocorticoid feedback inhibition of CRH secretion may occur, so that glucocorticoid elevations may be sustained (Dallman et al., 2003).

Although numerous adverse events have been found to promote HPA activation, it seems that certain stressors are particularly effective in provoking such outcomes, including situations that are viewed as uncontrollable, unpredictable, and threatening to self-concept (Biondi, \& Picardi, 1999). In this regard, activation of the stress response depends strongly on how a stressor is interpreted. Demanding situations involving a threat to self-concept (social evaluation by an audience and threat of public embarrassment or failure) specifically trigger activation of the HPA axis and a high level of cortisol release (Dickerson, \& Kemeny, 2004), and are associated with increased feelings of shame and lower social self-esteem (Dickerson, Gruenewald, \& Kemeny, 2004; Grunewald, Kemeny, Aziz, \& Fahey, 2004).

Stress and Eating. The type and/or severity of a stressor experienced may influence eating behaviours; mild stressors may provoke overeating, whereas severe stressors are more likely to produce under-eating (Greeno \& Wing, 1994; Torres \& 
Nowson, 2007). Self-threatening, interpersonal and work-related hassles have been associated with increased snacking and overeating, while physical stressors have been related to decreased food consumption (Heatherton, Herman, \& Polivy, 1991, 1992; O’Connor, Jones, Conner, Ferguson, \& McMillan, 2008). Gender differences regarding stress and eating have also been found; whereas women tend to consume more calories, fat, sugar, and snack foods under stressful circumstances, (McCann, Warnick, \& Knopp, 1990; Wardle, Steptoe, Oliver, \& Lipsey, 2000), men appear to maintain or slightly decrease food intake and report a preference for meal-related nutrient dense foods (such as steak, casseroles) (Bellisle et al., 1990; Grunberg, \& Straub, 1992).

Differences in physiological reactions to stress have also been associated with the tendency to overeat in stressful situations. Individuals who show high cortisol reactivity in response to stressors have been found to overeat in response to stress and negative emotions, compared to individuals with lower cortisol reactivity. Epel, Lapidus, McEwen and Brownell (2001) found that women with higher cortisol reactivity in response to stressors consumed significantly more calories after being exposed to a series of stressors that were cognitively demanding and ego-threatening, and consumed overall higher amounts of sweet foods whether exposed to a stressor or not. Likewise, Newman, O'Connor, \& Conner (2007), reported that daily hassles were associated with increased snacking in individuals with high cortisol reactivity.

Animal models of stressor-related eating have revealed that eating behaviours vary depending on the type of stressor, whether it is acute or chronic, and the specific type of food available. Rats exposed to chronic stressors typically reduce food intake and lose weight (Harris, Palmondon, Leshin, Flatt, \& Richard, 2006); however, when 
palatable high-energy foods are available, stressful events typically increase food intake. Animal studies using models of social stressors have shown varied effects on food intake depending on the specific paradigm used and the species investigated. In a visible burrow model of dominance-subordination, both dominant and subordinate rats were found to reduce food intake and lose weight; however, the subordinate rats lost more weight and during recovery regained most of their weight as fat, in comparison with the dominant rats, indicating that the subordinate rats were experiencing more stress (Tamashiro et al., 2004).

In a study of hamsters using the resident-intruder model of social stress, sociallydefeated hamsters showed increased food intake and weight compared to controls after repeated stress-exposure. Defeated hamsters initially showed increased cortisol concentrations; however the cortisol response decreased with repeated exposure to the stressor (Foster, Solomon, Huhman, \& Bartness, 2006). Bartolomucci et al. (2009) reported that social status (subordinate or dominant) in mice under chronic stress affected food intake, locomotor activity and sympathetic activation in adipose fat pads. Chronic stress was associated with increased food intake in both subordinate and dominant animals; however subordinate animals showed decreased motor activity, greater intake of high fat palatable food, and increased weight gain in comparison with dominant mice.

Dallman et al. (2003) found that chronic stressors and associated elevated glucocorticoid and insulin levels in rats were related to increased salience of pleasurable activities, and a drive to ingest palatable high-energy foods (sucrose and lard), resulting in abdominal obesity. It is thought that increased abdominal fat stores lead to signal inhibition of catecholamines in the brainstem and decreased $\mathrm{CRH}$ expression by the 
hypothalamus, acting to reduce the damage caused by chronic activation of the HPA-axis. Thus, Dallman et al. proposed that humans eat high energy "comfort foods" in an attempt to decrease activity of the body's habitual response to chronic stress. Indeed, a highcarbohydrate diet has been associated with decreased plasma cortisol levels (Anderson et al., 1987), and humans who are depressed and overeat have decreased catecholamine levels, CRH and HPA activity.

\section{Individual differences in eating behavior}

According to the individual differences model, factors within individuals (depression and anxiety, coping strategies, impulsivity, eating restraint) determine whether or not someone will overeat in response to stress and negative affect (Greeno \& Wing, 1994).

Depression and Anxiety. In response to stressors, physiological changes occur that have been associated with continuing anxiety symptoms and increased risk of depression (Anisman \& Zacharko, 1982; Brown, Bifulco \& Harris, 1987; Chen, Siu, Lu, Cooper, \& Phillips, 2009; Wheatley, 1998; Hammen, Brennan, Keenan-Miller, Hazel, \& Najman, 2010; Kendler, Karkowski \& Prescott, 1999; Suarez-Morales \& Lopez, 2009). Major depression has been associated with altered HPA functioning and cortisol hyperactivity in response to stressors (Chopra et al., 2009; Hinkelmann et al., 2009; Stokes, 1995; Wichers et al. 2008); however depression with atypical features has been related to cortisol hypoactivity (Anisman, Ravindran, Griffiths, \& Merali, 1999; Gold, \& Chrousos, 2002). Stressors have marked effects on physical and mental health, and can also have indirect effects by influencing behaviours that impact health, such as eating and sleeping. 
As already indicated, considerable inter-individual variability exists in this respect, as stressful events promote eating in some individuals, while having the opposite effects in others. Likewise, clinical depression may present with different eating symptoms. Specifically, symptoms of typical depression include reduced eating and sleeping, whereas atypical depression is characterized by reversed neurovegetative symptoms, including increased sleep and food intake. Atypical depression is also characterized by mood reactivity and rejection sensitivity, meaning that mood can be uplifted by positive events, but is also very sensitive to being influenced by negative events and interactions such as social rejection (Nierenberg, Alpert, Pava, Rosenbaum, \& Fava, 1998).

Emotional Eating. As alluded to earlier, there are individuals who tend to eat in response to stressful stimuli. In this regard, emotional eaters overeat specifically when they encounter self-evaluative stressors and those that provoke negative mood or affect. Overeating in response to negative emotions can begin as early as childhood and can continue into adolescence (Goossens, Braet, Van Vlierberghe, \& Mels, 2009; NguyenRodriguez, Chou, Unger, \& Spruijt-Metz, 2008). For instance, it was reported that that in overweight children and teenagers, emotional eating mediated the relationship between anxiety and loss of control over eating and that increased depression was associated with emotional eating (Goossens et al., 2009). Overeating in response to negative emotions can continue or develop in adulthood and has been reported by obese adults (Van Strien \& Ouwens, 2003; Manzoni et al., 2009), women with eating disorders (Agras \& Telch, 1998), and normal-weight dieters (Polivy, Herman \& McFarlane, 1994). In general, women tend to score higher on emotional eating than do men (Oliver, Wardle, \& Gibson, 2000). 
According to studies using the The Dutch Eating Behaviour Questionnaire (van Strien, Frijters, Bergers, \& Defares, 1986), which measures emotional eating and restrained eating on separate subscales, emotional eating was a better predictor of eating in response to stressors. Likewise, in evaluating the effects of individual difference variables (restrained eating, emotional eating, external eating, disinhibition, obesity, and gender) on eating in response to daily hassles, it was found that emotional eating was the pre-eminent moderating variable of snacking in response to stressors (O'Connor et al., 2008). In a laboratory setting, experimentally induced negative affect has been shown to provoke eating in both obese and normal-weight emotional eaters (Oliver, Wardle \& Gibson, 2000; Van Strien \& Ouwens, 2003). Along with being prone to overeating in response to stressors, emotional eaters tend to choose unhealthy foods that are high in fat and sugar. In a retrospective study examining women's self-reported changes in intake of snack foods in response to specific and general stressors, high emotional eating, but not restrained eating, was associated with increased intake of high-fat snack foods, such as chips, chocolate and cookies (Wallis \& Hetherington, 2009).

Blum et al. (2000) proposed that emotional eating and impulsivity could both be the result of an underlying reward deficit syndrome, with associated higher receptivity to the reinforcing values of alcohol and drugs, and proneness to impulsive and destructive behaviours. Binge eaters have been found to endorse other impulsive behaviours, such as substance abuse more than those who do not engage in binge eating behaviours (Schwarze, Oliver, \& Handal, 2003). High sensitivity to reward has also been found to be significantly related to food craving and body weight (Franken \& Muris, 2005). Recent studies in rats have indeed shown that overconsumption of palatable food triggers an 
addiction-like change of dopamine receptors (particularly D2 receptors) in brain reward systems, which drives the development of compulsive eating (Johnson \& Kenny, 2010). Like other addictive behaviours, emotional eating is also very resistant to change, even after years of diet intervention in individuals whose eating behaviours pose a health risk (Van Strien \& van de Laar, 2008).

Differences in brain activation indicate that emotional eaters may have increased sensitivity to the rewarding properties of food, specifically when experiencing negative emotions. Using functional magnetic resonance imaging, Bohon, Stice, \& Spoor (2009) found that emotional eaters showed activation in brain regions associated with anticipatory and consummatory reward in response to receipt of a milkshake, but only during a negative mood induction. In contrast, decreased activation occurred in these regions during a negative mood induction among non-emotional eaters.

Emotional eating as a coping mechanism. Perspectives regarding emotional eating have included the view that "emotional eaters" overeat as a maladaptive form of coping with negative mood and/or experiences.

Related to the view that eating may serve in a coping capacity, the psychosomatic perspective posits that emotional eaters overeat as a method of alleviating negative mood states, such as anxiety, sadness, and loneliness (Bruch, 1973; Kaplan \& Kaplan, 1957). Emotional eating has indeed been related to symptoms of anxiety and depression, suicidal ideation and behaviour, as well as problems with intimacy and sexuality (Ouwens, van Strien, \& van Leeuwe, 2009; Van Strien, Schippers, \& Cox, 1995).

Binge eating, which is strongly related to emotional eating, is often triggered by dysphoric moods, and is associated with depression and anxiety (DSM-IV-TR, 2000; 
Lynch et al., 2000). In overweight men and women seeking treatment for Binge Eating Disorder, greater emotional eating has been related to more frequent binge eating episodes, as well as more frequent and severe concerns about eating, shape and weight, disinhibition and hunger. Moreover, anxiety was the most frequently reported emotion associated with overeating, whereas happiness was the least reported emotion. Emotions of sadness, loneliness, tiredness and anger also triggered emotional eating in both men and women; however women reported overeating in response to loneliness significantly more frequently than did men (Masheb, \& Grilo, 2006).

It has been suggested emotional eaters lack interoceptive awareness (the ability to discriminate between sensations and feelings, and between the sensations of hunger and satiety), and may therefore overeat in reaction to any discomfort or arousal state (Bruch, $1964,1973)$. After eating a pre-load of food, emotional eaters have actually been found to eat more, rather than less, and this has been strongly related to lack of interoceptive awareness (van Strien, Cleven, \& Schippers, 2000; van Strien \& Ouwens, 2003). Lack of interoceptive awareness is strongly related to alexithymia, which means the inability to express feelings with words, and usually involves a deficiency in understanding, processing, or describing emotions (Quinton, \& Wagner, 2005). Alexithymia, and more specifically the component of difficulty identifying feelings, has been found to be positively related to emotional eating (Larsen, Van Strien, Eisinga, \& Emgles, 2006; Van Strien, 2000) and more specifically has been found to be a moderator between experimental stress-induction and food intake (Van Strien \& Ouwens, 2007), as well as between depression and emotional eating (Ouwens, van Strien, \& van Leeuwe, 2009). Emotional eaters may misinterpret many sensations and feelings as hunger, and may be 
unable to differentiate properly between internal sensations of satiety and hunger, again leading them to overeat.

According to the escape theory (Heatherton \& Baumeister, 1991), emotional eaters consume food in order to shift attention away from a stimulus that they interpret as ego-threatening. Emotional eaters focus on salient external stimuli (i.e., food) in order to escape abnormally high levels self-awareness, thus escaping the negative thoughts and feelings that accompany this self-awareness (Wallis \& Heatherington, 2004). The idea that emotional eaters use food as an escape from stimuli that they interpret as threatening to the self is in line with cognitive theories which posit that individuals who engage in maladaptive eating behaviours, such as emotional overeating and dietary restraint, show a selective bias towards negative stimuli, particularly those that are threatening to their self-concept (Williams, Watts, MacLeod, \& Matthews, 1997; Williams, Mathews, \& MacLeod, 1996). In this regard, binge eating has been associated with low self-esteem (Antony et al., 1994; Nerzog, Nussbaum, \& Marmor, 1996; Paxton \& Diggens, 1997; Schwarze, Oliver, \& Handal, 2003) and emotional eaters have been found to overeat specifically in stressful situations involving evaluation or negative self-referent information (Heatherton, Herman, \& Polivy, 1991, 1992; Oliver, Wardle, \& Gibson, 2000; Polivy \& Herman, 1999). Oliver et al (2000) found that stressed emotional eaters consumed significantly more sweet, high-fat, and energy dense foods during anticipation of a self-evaluative stressor (public speaking task), than did non-emotional eaters, and those not exposed to the task. Thus, it seems that emotional eaters have high selfexpectations and negative perceptions of how they are viewed by others, leading to emotional distress and high self-awareness. This, in turn, leads to increased sensitivity to 
negative self-referent information, leading to overeating as a form of escape from selfawareness (Heatherton \& Baumeister, 1991).

Emotional eating should be distinguished from yet another risk factor for excessive eating, namely that of restrained eating. Restrained eating, the deliberate cognitive control and restriction of food intake with the goal of losing or maintaining body weight, has consistently been found to be a risk factor for overeating in response stressors (Cools, Schotte, \& McNally, 1992; Frost, Goolkasian, Ely, \& Blanchard, 1982; Heatherton, Herman, \& Polivy, 1991). In laboratory settings, restrained eaters have been observed to overeat in response to cognitively demanding tasks as well as situations threatening self-concept (Walis \& Hetherington, 2004). Lowe \& Kral (2006) proposed that decreased control over food consumption occurs when cognitive resources usually aimed at controlling food intake are taxed by the demands of a stressor (intellectually and/or emotionally). In contrast with emotional eaters who appear to respond primarily to emotionally salient stressors, restrained eaters overeat in response to a variety of stressors. Of course, these categories are orthogonal, and hence it should be possible to be an emotional eater during the course of a restrained period.

\section{Food craving}

Food craving, which comprises an intense desire or urge to eat a specific food is fairly common, especially in women (Weingarten \& Elston, 1990), and has been strongly associated with emotional and external eating, difficulty identifying feelings, neuroticism, and the provocation of unplanned and overeating behaviour (Burton, Smit \& Lightowler, 2007; Gendall, Joyce, Sullivan, \& Bulik, 1998; Hill, Weaver \& Blundell, 1991; Macht \& 
Mueller, 2007; Muller, Dettmer, \& Macht, 2008). Food cravings have been found to be triggered by negative mood (Hill, Weaver, \& Blundell, 1991), as well as external cues such as the sight or smell of a particular food (Fedoroff, Polivy, \& Herman, 2003). Individuals who are depressed or experiencing emotional distress consistently report craving and preferring sweet foods high in carbohydrates and fat, and this preference intensifies as individuals become more depressed (Fernstrom, Krowinski, \& Kupfer, 1987). In comparison with non-depressed individuals, intake of carbohydrates is greater in depressed individuals and intake largely comprises sugars (Christensen \& Somers, 1996). Similar cravings are reported by individuals with seasonal affective disorder and premenstrual syndrome, both of which are characterized by depression as a primary symptom (Christensen, 2001).

Carbohydrate Craving. Carbohydrate craving is the most commonly reported craving (Christensen, 2001) and is often associated with emotional eating. Women who report a high frequency of emotional eating episodes of high-carbohydrate foods, display a preference for carbohydrates following a negative mood induction and show a significant reduction in dysphoria after consumption (Spring et al., 2008). Also, the kinds of carbohydrate foods that are typically reported as being craved are high in sugar and fat (Drewnowski, Kurth, Holden-Witse, \& Saari, 1992), thus making it impossible to know whether it is specifically the carbohydrates being craved, or perhaps more likely, the combination of carbohydrates with sugar and fat.

It has been proposed that carbohydrate craving precedes emotional eating episodes because the consumption of carbohydrates may work to naturally regulate mood. High-carbohydrate, low-protein meals may influence mood through an insulin- 
mediated increase in blood plasma levels of tryptophan, a precursor in the synthesis of serotonin, a neurotransmitter involved in mood regulation (Fernstrom \& Wurtman, 1971, 1972; Fernstrom, \& Fernstrom, 1995; Wurtman \& Wurtman, 1988). The ingestion of carbohydrates, possibly through its actions on brain serotonin levels, seems to be especially rewarding for individuals with depression (which involves low levels of serotonin). Increased craving for carbohydrates has been reported by depressed individuals, and it has been proposed that some individuals ingest carbohydrates as a form of "self-medication" (Wurtman, 1988; Wurtman \& Wurtman, 1995).

The data linking carbohydrate ingestion and serotonin synthesis need to be considered with caution because the carbohydrate-induced rise in brain tryptophan level and serotonin formation is blocked when more than five to six percent protein is added to the meal or if the carbohydrate meal is ingested within two hours of a protein meal (Fernstrom, 1988; Fernstrom, \& Fernstrom, 1995; Wurtman \& Wurtman, 1988).

Regardless, increased overall carbohydrate intake has been related to decreased anxiety and depression in obese women (Pellegrin et al., 1998) and diets low in carbohydrates and higher in protein have been associated with decreased mood, and low tryptophan/large neutral amino acids ratio (De Castro, 1987; Schweiger et al., 1986).

\section{The Present Investigation}

Considerable research has focused on the effects of stress on eating behaviour, and the individual differences that mediate the relationship between various types of stressors and overeating. Although it has been reported that emotional eaters react to selfevaluative stressors, which induce negative emotions, research needs to be conducted to 
identify other potential factors influencing emotional eating behaviour. The purpose of the present investigation was to examine the relationships between several variables potentially contributing to emotional eating in response to stressors, including psychological factors (mood, depressive symptomatology, craving), and physiological factors (cortisol reactivity), in order to gain a better understanding of the relationships that may affect individual responses to a self-evaluative stressor and possibly contribute to emotional eating.

The present investigation comprised a laboratory study, which assessed responses to a self-evaluative stressor (anticipation of giving a speech and performing a mentalmath task in front of a panel of judges) and included measures of salivary cortisol at four different time points.

It was hypothesized that

(1) In response to stressors, or anticipation of stressors, emotional eaters would report greater emotional responses, particularly shame and anxiety.

(2) Emotional Eating would be related to increased food craving (in general, and specifically for carbohydrates and sugar) in the stressor condition.

(3) Emotional Eating would be associated with greater cortisol reactivity in response to the stressor and this relationship will be mediated by feelings of shame (immediately post-stressor) 
(4) Depressive symptomatology would be positively related to cortisol reactivity in response to the stressor. This effect was expected to be stronger for atypical depressive symptomatology, than for typical depressive symptomatology.

\section{Methods}

Study 1

Participants

Undergraduate female students, aged $18-32$ years $(n=72, M$ age $=19.99$ years $S D=2.48$ ) were recruited as participants for a study on student responses to challenging situations. Participants were told that they would be asked to fill out a questionnaire booklet, to perform a short task and to provide 4 saliva samples (used for the analysis of stress hormones) so that an analysis could be done to assess behavioral and physiological responses to the task. Participants received $1.5 \%$ course credit towards an Introductory Psychology course as compensation for participating in the study.

Procedure

Subjects were tested during the fall and winter semesters of the 2008-2009 academic year (December - April) in groups of 1 to 3. Groups were randomly assigned to either a Stressor or Control condition and tested individually. At the outset of the experiment participants received a full description of the study and an informed consent form was read and signed before beginning the session. Participants were then asked to fill out a battery of questionnaires divided into three sections. The first section included background and medical information (including information relevant to interpretation of 
the cortisol levels), questionnaires assessing depressive symptoms, with additional items included to obtain information regarding atypical depression (Beck Depression Inventory BDI; Beck, Ward, Mendelson, Mock, \& Erbaugh, 1961), general food cravings (State) General Food Cravings Questionnaire; Nijs, Franken \& Muris, 2006), and eating habits (Dutch Eating Behavior Questionnaire, DEBQ; Van Strien, Frijters, Bergers \& Defares, 1986).

After the first set of questionnaires was completed, subjects provided the first saliva sample (sample A), which served as a baseline measure of cortisol levels. Subjects in the stressor condition were then exposed to a manipulation based on the Trier Social Stress Test (Kirschbaum, Pirke, \& Hellhammer, 1993), a protocol used to induce moderate psychological stress. Subjects were told that they would be asked to prepare, and then give a speech about their employment potential, then do a brief math task, in front of a 6-person panel consisting of 3 professors and 3 graduate students. They were told that they have the next 15 minutes to prepare this speech, and that they would be evaluated on their presentation. Subjects in the control condition were told that they would be given word and number games to complete. They were told that they would have 15 minutes to complete the word and number games, and that they would not be evaluated on their performance. Subjects had the option of looking through neutral content magazines if they finished early.

At the end of the 15 minute preparation phase, participants provided saliva sample B. Those in the stressor condition were then told that there were not enough graduate students and professors to complete the panel at the current time, and that they would no longer be asked to perform the speech. Whereas the Trier Social Stress Test usually 
consists of an anticipation period of ten minutes, followed by a test period of ten minutes, only the anticipation period was used as a stressor in the present study. Subjects in the control condition would then be asked to stop filling out the word and number games if they had not already finished. To assess whether the manipulation was effective, subjects were asked to complete questionnaires that included initial mood ratings (Positive and Negative Affect Schedule with additional adjectives, PANAS; Watson, Clark \& Tellegan, 1988), state anxiety (State-Trait Anxiety Inventory, STAI; Speilberger, 1983), a stress appraisal measure (Stress Appraisal Measure, SAM; Peacock and Wong, 1986), as well as specific food cravings questionnaires (Food Craving Inventory with additional food options, FCI; White, Whisenhunt, Williamson, Greenway \& Netemeyer, 2002, and State General Food Cravings Questionnaire; Nijs et al., 2006)

Ten minutes afterward, participants provided saliva sample C. They were then asked to complete additional questionnaires. Ten minutes later, participants provided saliva sample D, and were asked to complete a second set of mood (PANAS; Watson et al., 1988) and food cravings questionnaires (FCI; White et al., 2002; State General Food Cravings Questionnaire; Nijs et al., 2006).

At the end of each session, participants were debriefed and provided with contact information if they wished to obtain more information about the study, had any ethical concerns, or if they wished to seek help related to personal well-being or student skills. Participants were then awarded academic credit. 


\section{Measures}

Depression. A modified version of the Beck Depression Inventory (BDI; Beck, Ward, Mendelson, Mock, \& Erbaugh, 1961) was used to assess for the presence and severity of depressive symptoms. The 24-item scale was used, which is comprised of the regular 21 items. A total score of 21 items was used to determine the degree of typical depressive symptoms and a total score using additional items was used to assess for symptoms of atypical depression. The 21 -item scale measuring typical depression demonstrated high internal reliability (Cronbach's $\alpha=.82$ ). Additional items were included that reflected atypical depressive symptoms. These items were derived from the 28-item Hamilton Depression inventory; however, these items had relatively low internal consistency (Cronbach's $\alpha=.56$ ).

Mood. The Positive and Negative Affect Schedule with additional adjectives, (PANAS; Watson, Clark \& Tellegan, 1988) is a questionnaire composed of 42 mood adjectives. Subjects indicate how they feel at that moment by rating each adjective on a scale from 0 "Not at all" to 6 "Extremely". Items divide into six factors: anger, guilt, shame, sadness, anxiety, and disgust). The current study focused on the shame and anxiety subscales. The alpha reliabilities for the subscales were .75 and .84 , respectively.

Anxiety. The "State" portion of the State-Trait Anxiety Inventory (STAI;

Speilberger, 1983) is composed of a 20-item scale with ratings from 1 "Not at all" to 4 "Very Much So". Total scores were calculated for State anxiety after re-coding items that had reversed values. There was high internal reliability with a coefficient alpha of .93 . Higher ratings on "State" Anxiety of the STAI, by subjects in the Stressor condition 
when compared to the Control condition would indicate that the anticipation of the Trier Social Stress Test elicited anxiety and thus, was effective as a stressor.

The Stress Appraisal Measure (SAM; Peacock and Wong, 1986) assesses subject appraisals of the task they just completed by answering 29 questions on a scale from 1 "Not at all" to 5 "Extremely". Peacock and Wong (1990) identified seven dimensions to the scale (Threat, Challenge, Centrality, Controllable-by-self, Controllable-by-others, Uncontrollable-by-anyone, Overall perceived stress) with internal consistency reliability coefficients ranging from .51 to .90 for the seven scales. The questionnaire was used to determine the effectiveness of the stressor; however, analyses were not included for the purpose of the present thesis. Higher ratings on the SAM for "Threat" and "Overall perceived stress" by subjects in the Stress condition when compared to the Control condition, indicated that the Trier Social Stress Test was effective as a stressor. Internal consistency reliability coefficients were .74 for Threat and .81 for Challenge.

Food craving. General food craving was measured using the General Food Cravings Questionnaire, State (GFCQ; Nijs, Franken \& Muris, 2006) The GFCQ State questionnaire is composed of 15 items on a rating scale from 1 "Strongly Disagree" to 5 "Strongly Agree" that measures general food craving at the specific moment in time when the questionnaire is completed, and divides into five factors [An intense desire to eat (Cronbach's alpha = .97), Anticipation of relief from negative states and feelings as a result of eating (Cronbach's alpha $=.83$ ), Craving as a physiological state (Cronbach's alpha $=.78)$, Obsessive preoccupation with food or lack of control over eating (Cronbach's alpha $=.82$ ), and Anticipation of positive reinforcement that may result from eating (Cronbach's alpha $=.84)]$. The Cronbach's alpha for the full scale was .94 . 
Subjects completed the GFCQ State Questionnaire immediately following the 15-minute task (speech preparation in the stressor condition; word and number games in the control condition), as well 20-minutes later.

At this time, subjects also completed the Food-Craving Inventory (FCI; White, Whisenhunt, Williamson, Greenway \& Netemeyer, 2002), a list of 38 foods (additional options included for this study). Subjects were asked to rate their degree of craving for each type of food on a scale from 1 "Not at all" to 5 "Extremely". Factor analyses by White et al. (2002) yielded four factors (high fats, sweets, carbohydrates/starches, and fast-food fats), and an additional factor of "healthy food" was added for the purposes of this study. Coefficient alphas ranged from .77 to .94 for the five subscales as well as .94 for the total score of all items, indicating good internal consistency.

Eating Behaviour. The Dutch Eating Behavior Questionnaire (Van Strien, Frijters, Bergers \& Defares, 1986) includes scales measuring emotional eating (13-items), restrained eating (10-items), and external eating (10-items). Mean scores on the emotional eating sub-scale were calculated and used in subsequent analyses. Cronbach's alpha was .96 for the emotional eating sub-scale, indicating high internal reliability.

Cortisol Response. The cortisol response is another measure of the effectiveness of the manipulation (anticipation of giving a speech) used as a stressor in the present investigation. The Trier Social Stress Test has been found to reliably lead to two- to fourfold elevations above baseline levels of salivary cortisol (Kirschbaum, Pirke, \& Hellhammer, 1993). In the present study, four salivary cortisol samples were taken from each subject [(A) baseline sample taken before task, (B) immediately after the 15-minute task, (C) 10-minutes post-task, and (D) 20-minutes post-task]. All samples were stored at 
$-30^{\circ} \mathrm{C}$ immediately after the session. Samples were subsequently analyzed, in duplicate, using assay kits obtained from ICN Biochemicals using $\mathrm{I}^{125}$ as the radioisotope marker.

Ratio scores of cortisol levels were taken to determine the degree of the stress response in reaction to the speech preparation task (10-minutes post-stressor: baseline, and 20-minutes post-stressor: baseline), with a higher value indicating a greater stress response. Ratio scores control for individual differences naturally present in diurnal cortisol levels (Smyth et al., 1997). Difference scores (10-minutes post-stressor-baseline) were also used in analyses.

As cortisol takes approximately 20 minutes to be evident in saliva (SchmidtReinwald, et al., 1999), the sample taken 10 minutes following the end of the 15 -minute task (anticipation and preparation of a speech) was used to represent the full physiological stress reaction to the stressor.

\section{Results}

\section{Descriptives}

Levels of Emotional Eating Behaviour (measured by scores on the Dutch Eating Behaviour Questionnaire; DEBQ wherein scores could range from 0 to 4) were moderate within the present sample $(M=1.77, S D=.99)$. The Mean for total scores on the Beck Depression Inventory was $8.07,(\mathrm{SD}=5.61)$, with a range from 0 to $25.68 .1 \%$ of the sample were in the "Not depressed" range (total score of $0-9$ ), $25 \%$ in the "MildModerate depression" range, and 6.9\% in the "Moderate-Severe depression" range. The mean total score for Atypical depressive symptomatology was $3.89,(\mathrm{SD}=2.46)$. The maximum possible score for items measuring atypical depression is 17 . An independent 
groups t-test indicated that there were no differences between stressor and control groups in terms of emotional eating scores, $t(130)=-.41, n s$, or atypical depressive symptomatology, $t(72)=-.40, n s ;$ however there was a significant difference in typical depressive symptomatology, $t(130)=.2,37, p<.05$, with a higher mean in the control group (see Table 1).

Table 1.

Descriptive Statistics (Means, Standard Deviations, and Ranges) as a Function of Condition.

Stressor Condition $\quad$ Control Condition

Emotional Eating $M \quad S D \quad$ Range $M \quad S D$ Range

1.81

1.05

4.00

1.72

$.93 \quad 3.54$

Typical Depression 6.63 5.66 25.00 9.68 $5.18 \quad 21.00$

Atypical Depression 4.00

2.85

11.00

3.76

$1.99 \quad 9.00$

Emotions of anxiety, and shame in response to a self-evaluative stressor

It was hypothesized that emotional eaters would report higher levels of shame and anxiety in response to the stressor (preparation and anticipation of giving a speech and performing a mental-math task in front of a panel consisting of three professors and three graduate students). Mood ratings were assessed by participant completion of a modified version of the PANAS (Watson, Clark \& Tellegan, 1988), as well as the State Anxiety Questionnaire (Speilberger, 1983), immediately post-task (Time A) and 20-minutes posttask (Time B). Total scores for PANAS anxiety ratings and the State Anxiety questionnaire were moderately correlated, $r=.68, p<.01$; therefore, only PANAS anxiety ratings were used in subsequent analyses. 
As seen in Table 2, Stressor condition was a significant predictor of feelings of anxiety reported immediately post-task, with participants exposed to the self-evaluative stressor reporting significantly greater levels of anxiety $(M=2.40, \mathrm{SD}=1.44)$ than participants in the control condition $(\mathrm{M}=1.16, \mathrm{SD}=1.44)$. However, emotional eating, reflected by scores on the Dutch Eating Behavior Questionnaire, was not a significant predictor of feelings of anxiety post-task, and there was no significant interaction between emotional eating and Stressor condition. Therefore, it seems that the anticipation of a public speaking task was effective at provoking anxiety in participants in the stressor condition, irrespective of emotional eating status.

Table 2.

Hierarchical Regression Assessing Immediate Feelings of Anxiety as a Function of Emotional Eating Behaviours and Condition (Stressor/Control).

\begin{tabular}{|c|l|llll|}
\hline Step & Variable & $\mathrm{b}$ & SE b & $\beta$ & R2 change \\
\hline 1. & Condition & $1.17^{* * *}$ & .213 & $.443^{* * *}$ & \\
& Emotional Eating & .229 & .150 & .163 & $.227^{* * *}$ \\
\hline \multirow{2}{*}{2.} & Condition & $1.23^{* * *}$ & .295 & $.446^{* * *}$ & \\
& Emotional Eating & .066 & .229 & .047 & \\
& Condition $\times$ Emotional Eating & .286 & .303 & .208 & .010 \\
\hline
\end{tabular}

${ }^{*} p<.05 ;{ }^{* *} p<.01 ;{ }^{* * *} p<.001$.

Emotional Eating and Feelings of Shame. As seen in Table 3, increased emotional eating was associated with significantly higher levels of shame immediately post-task; however, this result was not moderated by whether participants were exposed to the stressor or control task. 
We decided to further investigate the relationship between emotional eating and feelings of shame by evaluating the change in reported feelings of shame over the 20minute post-task period (Note: this next step was not taken in the case of anxiety scores, as they were not found to be significantly related to emotional eating). Difference scores were calculated by subtracting shame scores reported immediately post-task, from those scores reported 20-minutes later. A hierarchical regression was conducted to assess whether the relationship between emotional eating and shame difference scores was moderated by condition (stressor/control). The interaction between emotional eating and condition was significant (See Table 4). As seen in Figure 1, increased emotional eating was associated with a greater decline in reported levels of shame 20 -minutes poststressor. Thus it seems that emotional eaters report higher levels of shame in general, and that relief from feelings of shame after a stressor may vary as a function of emotional eating behaviour. 
Table 3.

Hierarchical Regression Assessing the Relation between Emotional Eating and Immediate Feelings of Shame as a Function of Condition (Stressor/Control).

\begin{tabular}{|c|l|llll|}
\hline Step & Variable & $\mathrm{b}$ & SE b & $\beta$ & R2 change \\
\hline 1. & Condition & .299 & .191 & .177 & \\
& Emotional Eating & $.258^{*}$ & .097 & $.300^{*}$ & $.124^{*}$ \\
\hline \multirow{2}{*}{2.} & Condition & .305 & .191 & .181 & \\
& Emotional Eating & .122 & .148 & .143 & \\
& Condition $\times$ Emotional Eating & .237 & .196 & .208 & .019 \\
\hline
\end{tabular}

${ }^{*} p<.05 ;{ }^{* *} p<.01 ;{ }^{* * *} p<.001$.

Table 4.

Hierarchical Regression Assessing the Relation between Emotional Eating and Change in Feelings of Shame over time (20-min) as a Function of Condition (Stressor/Control).

\begin{tabular}{|c|l|llll|}
\hline Step & Variable & $\mathrm{b}$ & SE b & $\beta$ & R2 change \\
\hline 1. & Condition & $-.519^{* * *}$ & .142 & $-.398^{* * *}$ & \\
& Emotional Eating & .258 & .097 & .300 & $.195^{* *}$ \\
\hline 2. & Condition & $-.528^{* * *}$ & .137 & $-.406^{* * *}$ & \\
& Emotional Eating & .071 & .107 & .106 & \\
& Condition $\times$ Emotional Eating & $-.331^{*}$ & .141 & $-.377^{*}$ & $.061^{*}$ \\
\hline
\end{tabular}

${ }^{*} p<.05 ;{ }^{* *} p<.01 ;{ }^{* * *} p<.001$ 


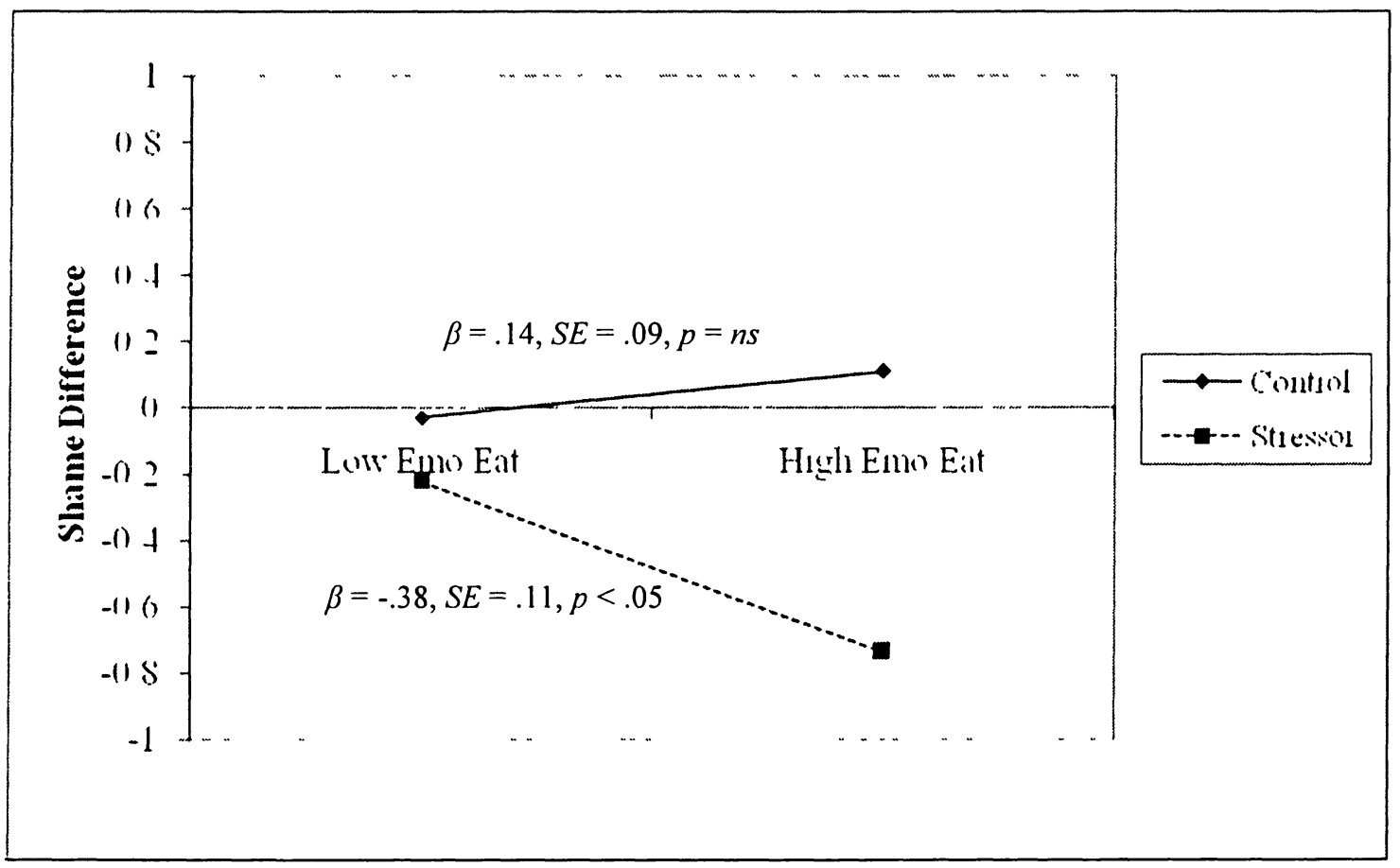

Figure 1. Hierarchical Regression lines showing the moderating effect of Condition (Stressor vs. Control) on the relation between Emotional Eating and feelings of Shame for the 20-minute period post task (Shame Time B - Shame Time A).

\section{Food Craving}

Relationships between Food Preferences and Food Cravings. It was of interest to determine if reported food cravings were consistent with food preferences, i.e., specific to individuals favourite type of food (Meat, Fruits and Vegetables, Dairy, Bread and Pasta, or Sweets). Correlation Analyses were conducted to examine relationships between Food Preferences (types of food ranked from 1 to 5) and Specific Food Cravings (Food Craving Inventory). Preference for sweets was moderately correlated with craving sweets immediately post-task $(R=-.480, p<.001)$, and preference for meat was related to craving high-fat foods immediately post-task $(R=-.275, p<.05)$. No other food preferences were significantly correlated with specific food cravings. 
A hierarchical regression was conducted in order to assess emotional eating and preference for sweets as predictors of craving sweets immediately post-task. As seen in Table 5, both emotional eating and preference for sweets were significant predictors of craving sweets post-task; however, the interaction between the two variables was not significant.

Table 5.

Hierarchical Regression Assessing Emotional Eating and Preference for Sweets as Predictors of Craving for Sweets immediately post-task.

\begin{tabular}{|c|l|llll|}
\hline Step & Variable & $\mathrm{b}$ & SE b & $\beta$ & $R^{2}$ change \\
\hline 1. & Emotional Eating & $.333^{*}$ & .132 & $.266^{*}$ & \\
& Sweets Preference & $-.359^{* * *}$ & .090 & $-.422^{* * *}$ & $.298^{* * *}$ \\
\hline \multirow{2}{*}{2.} & Emotional Eating & .429 & .282 & .343 & \\
& Sweets Preference & $-.357^{* * *}$ & .091 & $-.420^{* * *}$ & \\
& Sweets Preference $\times$ Emotional Eating & -.036 & .093 & -.086 & .002 \\
\hline
\end{tabular}

${ }^{*} p<.05 ;{ }^{* *} p<.01 ;{ }^{* * *} p<.001$.

Relations between Emotional Eating, Stress, and Food Craving. In the present investigation it was expected that emotional eaters would experience increased general and specific food cravings for carbohydrates and sugar (defined to participants as "an intense desire to consume a particular food (or food type) that is difficult to resist") in response to the stressor condition. Food craving was evaluated immediately post-task (Time A) and 20-minutes later (Time B). As seen in Table 6, emotional eating was significantly related to general food craving, obsessive preoccupation with food or lack of control over eating, anticipation of positive reinforcement that may result from eating, 
and anticipation of relief from negative states as a result of eating at Time A and B, as well as specific food craving for sugar (Time A and B) and carbohydrates (Time B) on the Food Craving Inventory. Emotional eating and general food craving were not related to specific food cravings for high fat, healthy, or fast food.

Table 6.

Study 1 Pearson Correlations among Emotional Eating, and General and Specific Food Cravings immediately post-task (A) and 20-minutes later (B). (Time $A$ above the diagonal, Time B below the diagonal)

\begin{tabular}{|c|c|c|c|c|c|c|c|c|c|}
\hline Varıable & 1 & 2 & 3 & 4 & 5 & 6 & 7 & 8 & 9 \\
\hline 1 Emotıonal Eatıng & $--\cdot$ & $354^{* *}$ & $302^{\circ}$ & $357^{* *}$ & $372^{*}$ & $203 n s$ & $161 n s$ & $350^{* *}$ & $221 n s$ \\
\hline $\begin{array}{l}2 \text { General Food } \\
\text { Craving (State) }\end{array}$ & $354^{* *}$ & --- & $760^{\cdots *}$ & $878^{\cdots *}$ & $866^{* \cdots}$ & $855^{\cdots *}$ & $867^{\cdots *}$ & $446^{\cdots}$ & $526^{\circ \cdots}$ \\
\hline 3 Preoccupation & $327^{*}$ & $718^{* * *}$ & --- & $585^{\circ \cdots *}$ & $590^{* * *}$ & $560^{\circ \cdots *}$ & $580^{\circ *}$ & $446^{* * *}$ & $526^{\cdots}$ \\
\hline $\begin{array}{l}4 \text { Antıcıpation } \\
\text { Relıef }\end{array}$ & $287^{*}$ & $878^{\cdots *}$ & $750^{\cdots *}$ & --- & $713^{\cdots}$ & $637^{\cdots *}$ & $764^{\cdots * *}$ & $452^{\cdots *}$ & $425^{\cdots \cdots}$ \\
\hline $\begin{array}{l}5 \text { Anticipation } \\
\text { Positive }\end{array}$ & $866^{\cdots}$ & $731^{* *}$ & $700^{\cdots \cdots}$ & $790^{* * *}$ & -- & $649^{* *}$ & $590^{* * *}$ & $361^{\circ *}$ & $471^{\cdots}$ \\
\hline 6 Desıre & $222^{+}$ & $840^{\circ * *}$ & $700^{* * *}$ & $700^{* * *}$ & $730^{\circ * *}$ & $\cdots$ & $643^{\cdots *}$ & $398^{* *}$ & $392^{*}$ \\
\hline $\begin{array}{l}7 \text { Physiological } \\
\text { Cravıng }\end{array}$ & $064 n s$ & $682^{\cdots}$ & $641^{\cdots *}$ & $766^{* * *}$ & $738^{* \cdots}$ & $684^{* * *}$ & --- & $341^{* *}$ & $506^{\cdots}$ \\
\hline \multicolumn{10}{|l|}{$\begin{array}{l}\text { Specific Food } \\
\text { Craving }\end{array}$} \\
\hline 8 Sweet & $350^{\circ}$ & $454^{* *}$ & $394^{*}$ & $339^{* *}$ & $369^{*}$ & $403^{* *}$ & $240^{\circ}$ & $\cdots$ & $563^{\cdots}$ \\
\hline 9 Carbohydrates & $295^{*}$ & $576 \cdots$ & $525^{\circ \cdots *}$ & $526^{\circ * *}$ & $582^{\cdots *}$ & $654^{\circ \cdots}$ & $514^{\cdots *}$ & $654^{* * *}$ & $\cdots$ \\
\hline
\end{tabular}

Psychological factors mediating the relationships between emotional eating and increased sugar and carbohydrate craving. As seen in Table 6, zero-order correlations revealed that three factors from the General Food Craving Scale (State) Scale (1) 
Anticipation of relief from negative states as a result of eating, (2) Anticipation of positive reinforcement that may result from eating and (3) Preoccupation with food or lack of control over eating were positively related to emotional eating and sugar craving immediately post-task. Regression analyses were conducted to assess these factors as possible mediators of the relationships between emotional eating and increased craving for sugar and carbohydrates. Preacher and Hayes' $(2004,2008)$ procedures for assessing simple and multiple mediation models were followed. Bias corrected and accelerated bootstrapping and the construction of confidence intervals were used to evaluate the direct, indirect, and total effects of the predictor variable (emotional eating) on sugar and carbohydrate craving post-task. These analyses were conducted with 5000 bootstrap samples in each analysis and, given the small sample size and consequently low power, $95 \%$ bias corrected confidence intervals.

Sugar craving immediately post-task. Simple Mediation analyses indicated that all three factors were significant mediators of the relation between emotional eating and sugar craving immediately post-task. A multiple mediation model was used (see Figure 2) to examine the total indirect effect of the three mediators together in the model, as well as to determine to what extent each variable mediated the relationship between emotional eating and sugar craving immediately post-task, conditional upon inclusion of the other mediators in the model. When Anticipation of relief, Anticipation of positive reinforcement, and Preoccupation were controlled in the relation between emotional eating and sugar craving, the direct relation was no longer significant. The total indirect effect (including all three mediators) was significant with a point estimate of .1923 (CI: .05 to .41$)$. The $95 \%$ bias corrected and accelerated confidence interval (CI) indicated 
that the total indirect effect (including all three mediators) was significant (CI: .05 to .41). Examination of $95 \%$ confidence intervals for specific indirect effects indicated that only Anticipation of relief from negative states as a result of eating was a significant mediator of the relationship between emotional eating and sugar craving immediately post-task, because the confidence interval for the mediated path did not overlap zero (CI: .02-.40). Whereas, Anticipation of positive reinforcement and Preoccupation did not significantly mediate this relation (i.e., CI for the mediated path overlapped zero). The mediated model was not moderated by condition, suggesting that emotional eating behaviours are related to feelings of Anticipation of relief from negative states as a result of eating, leading to increased sugar craving, regardless of whether participants are exposed to the stressor or control condition. 


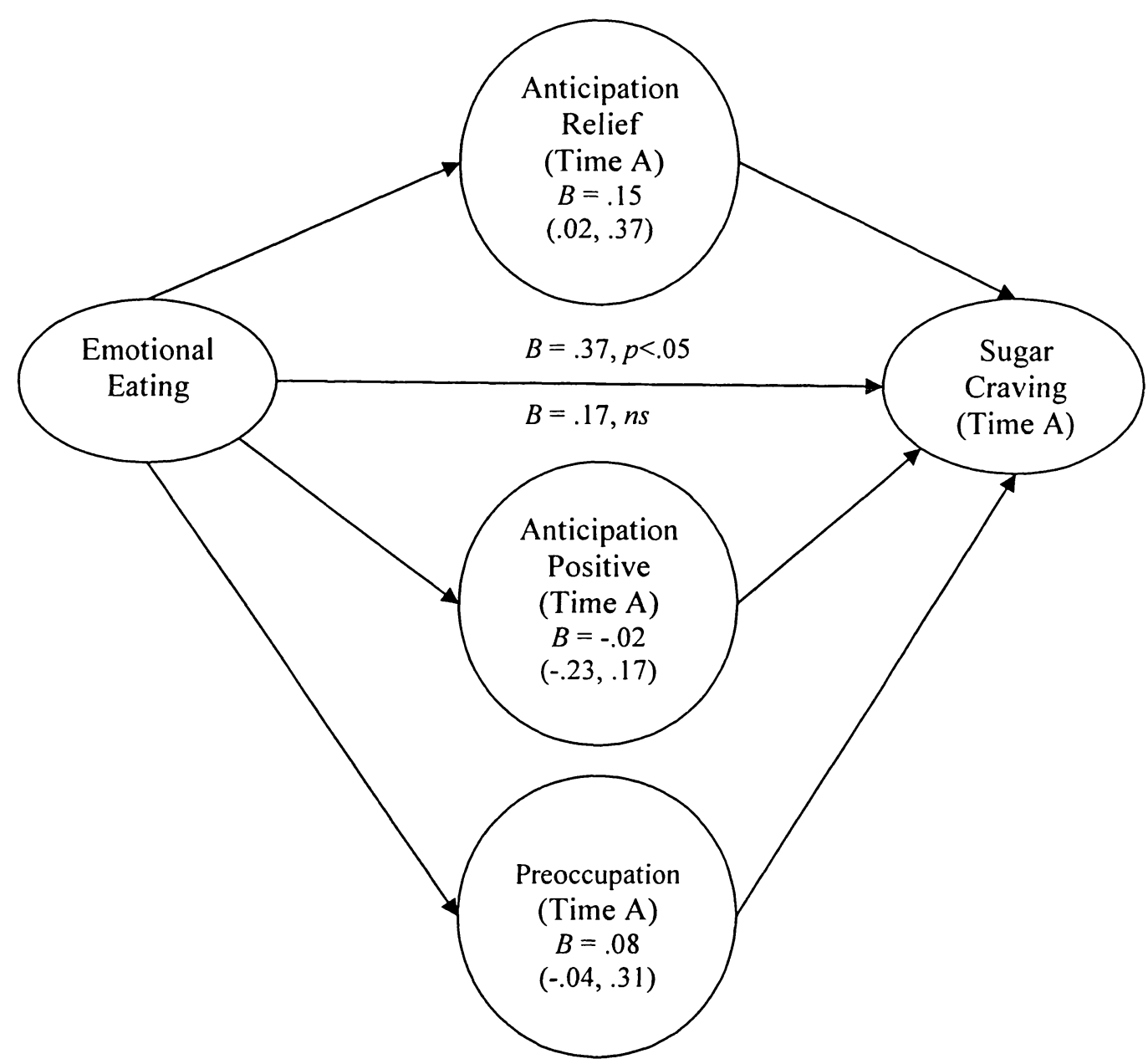

Figure 2. Anticipation of Relief from Negative States as Result of Eating, Anticipation of Positive Reinforcement that may result from Eating, and Preoccupation with Food or Lack of Control over Eating as Multiple Mediators of the relationship between Emotional Eating and Sugar Craving Immediately Post-task (Time A). (Confidence Intervals indicate that only Anticipation of Relief was a significant mediator above and beyond the other mediators in the model.)

Sugar craving 20-minutes post-task. Simple Mediation analyses using craving measures taken at Time B, revealed that anticipation of positive reinforcement that may result from eating was a significant mediator of the relationship between emotional eating 
and increased sugar cravings 20- minutes post-task (See Figure 3). Anticipation of relief, and Preoccupation with food or lack of control over eating, were not significant mediators.

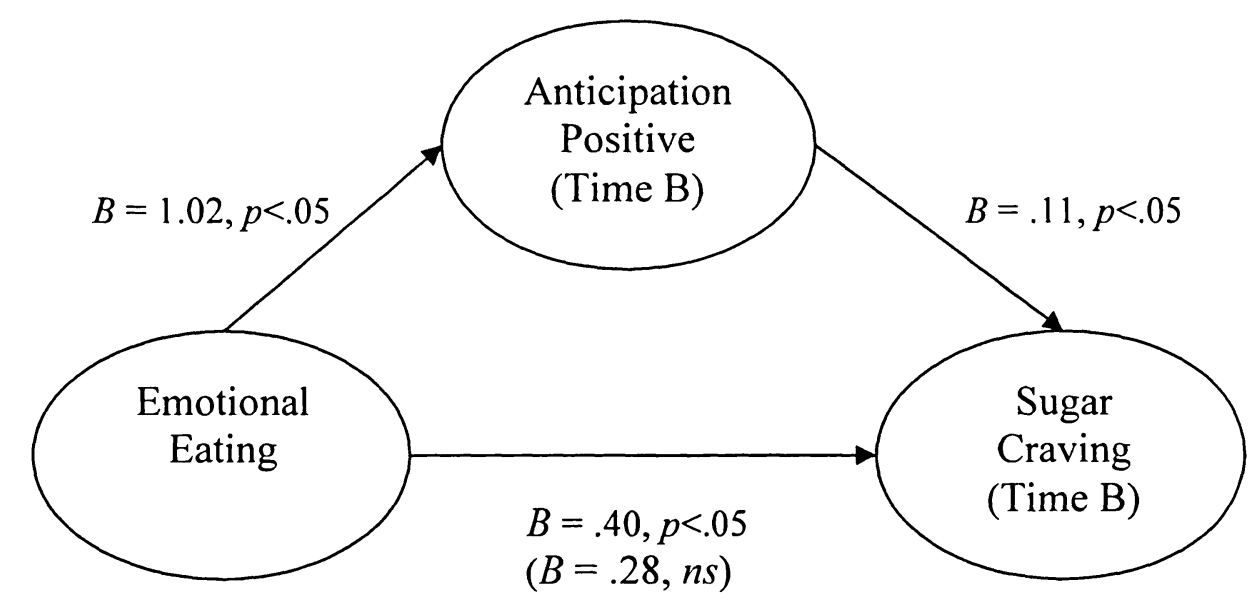

Figure 3. Anticipation of Positive Reinforcement that may result from Eating as a Mediator between Emotional Eating and Sugar Craving 20-minutes Post-task (Time B).

Carbohydrate craving 20-minutes post-task. Simple Mediation Models indicated that Anticipation of positive reinforcement that may result from eating, and Preoccupation with food or lack of control over eating were found to mediate the relationship between emotional eating and carbohydrate craving 20 -minutes post-task.

A multiple mediation model (see Figure 4) was used to tease apart the individual mediators of the relationship between emotional eating and carbohydrate cravings 20minutes post-task. The $95 \%$ bias corrected confidence intervals indicated that the total indirect effect (including both mediators) was significant (CI: .04 to .32). However, examination of confidence intervals for specific indirect effects indicated that only 
Anticipation of positive reinforcement that may result from eating was a significant mediator of the relationship between emotional eating and carbohydrate craving 20minutes post-task (CI: .01-.24), above and beyond Preoccupation. The mediated model was not moderated by condition.

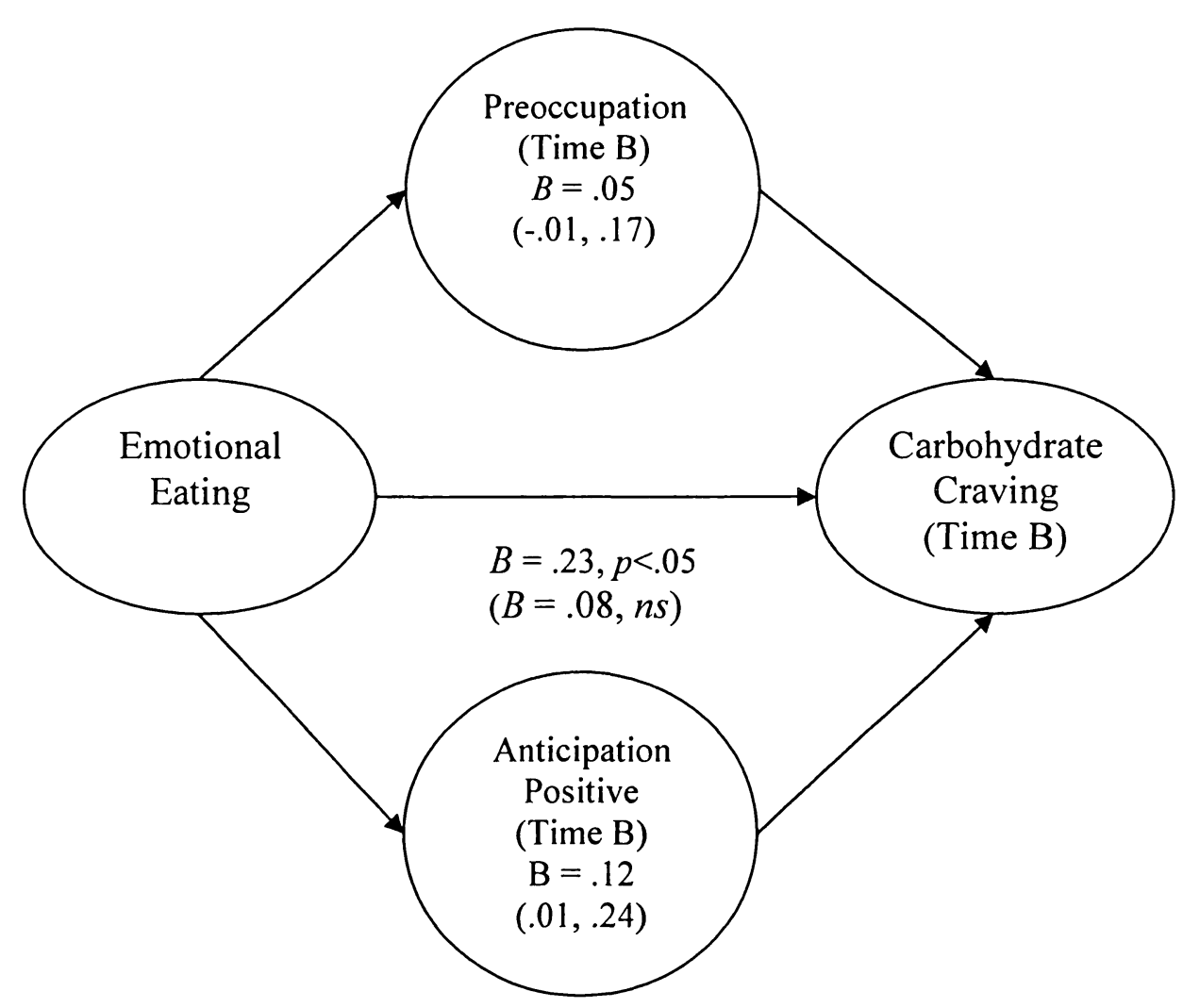

Figure 4. Anticipation of Positive Reinforcement that may result from Eating, and Preoccupation with Food or Lack of Control over Eating as Multiple Mediators of the relationship between Emotional Eating and Carbohydrate Craving 20-minutes Post-task (Time B). (Confidence Intervals indicate that only Anticipation of Positive Reinforcement was a significant mediator above and beyond Preoccupation.) 
Individual Differences in Cortisol Reactivity to the Stressor

Emotional Eating, Shame, and Cortisol Reactivity to the Stressor. It was expected that emotional eating would be associated with greater increases of cortisol in response to the stressor, and that this relationship may potentially be mediated by feelings of shame elicited by the stressor. However, the relationship between emotional eating and cortisol increase was not significant, $R=.051, p=.345$.

Depression, Shame, and Cortisol Reactivity to the Stressor. It was expected that individuals with greater depressive symptomatology would show increased cortisol reactivity in response to the stressor, and that this relationship would be mediated by feelings of shame. As seen in Table 7, a correlation analysis was conducted to determine the viability of the mediation model. Typical depressive symptomatology was found to be significantly related to increased cortisol 10 -minutes post-task $(R=.425, p<.001$ for cortisol difference scores, $R=.335, p<.01$ for cortisol ratio scores) and 20 -minutes post task $(R=.317, p<.05$ for cortisol difference scores, $R=.271, p<.05$ for cortisol ratio scores). In contrast, atypical depression was not significantly related to cortisol reactivity.

Feelings of shame reported immediately post-task were not significantly correlated with depressive symptomatology or increase of cortisol, and therefore shame immediately post-task was not a potential mediator of the relationship between typical depressive symptomatology and cortisol reactivity to the stressor.

A Hierarchical Regression analysis was run to determine whether the relationship between typical depressive symptomatology and increase of cortisol was moderated by condition (stressor/control). As seen in Table 8, typical depressive symptomatology was significantly related to an increase of cortisol, with condition as a moderator. 
Specifically, individuals reporting greater depressive symptomatology showed significantly higher increases of cortisol post-stressor (see Figure 5).

\section{Table 7.}

Pearson Correlations among Depressive Symptomatology, Feelings of Shame (immediately post-task and difference scores between 20-minutes post-task and immediately post-task), and Cortisol reactivity (difference scores and ratio scores between 10-minutes post-task and immediately post-task).

\begin{tabular}{|c|c|c|c|c|c|c|}
\hline Varıable & 1 & 2 & 3 & 4 & 5 & 6 \\
\hline \multicolumn{7}{|l|}{ Depressive Symptoms } \\
\hline 1 Typical & -.- & $416^{* * *}$ & $141 n s$ & $219^{+}$ & $425^{* *}$ & $335^{* *}$ \\
\hline 2 Atypical & $416^{\cdots *}$ & --- & $045 n s$ & $047 n s$ & $158 n s$ & $066 n s$ \\
\hline \multicolumn{7}{|l|}{ Feelings of Shame } \\
\hline 3 Immedıately post-task & $141 n s$ & $045 n s$ & -- & $-608^{\cdots *}$ & $106 n s$ & $051 n s$ \\
\hline 4 Difference scores & $219^{+}$ & $047 n s$ & $-608^{\cdots}$ & $\cdots$ & $-118 n s$ & $-023 n s$ \\
\hline \multicolumn{7}{|l|}{ Cortisol Reactivity } \\
\hline 5 Difference scores & $425^{\cdots *}$ & $158 n s$ & $106 n s$ & $-118 n s$ & $\ldots$ & $893^{\cdots *}$ \\
\hline 6 Ratıo scores & $335^{*}$ & $066 n s$ & $051 n s$ & $-023 n s$ & $893^{\cdots *}$ & $\cdots$ \\
\hline
\end{tabular}


Table 8.

Hierarchical Regression Assessing the Relation between Typical Depressive Symptomatology and Cortisol Ratio scores (10-min post-task: Baseline) as a Function of Condition (Stressor/Control).

\begin{tabular}{|c|l|llll|}
\hline Step & Variable & b & SE b & $\beta$ & $R^{2}$ change \\
\hline 1. & Condition & $.306^{*}$ & .143 & $.258^{*}$ & \\
& Typical Depressive Symptomatology & $.247^{* *}$ & .073 & $.406^{* *}$ & $.174^{* *}$ \\
\hline 2. & Condition & $.298^{*}$ & .137 & $.251^{*}$ & \\
& $\begin{array}{l}\text { Typical Depressive Symptomatology } \\
\text { Condition } \times \text { Typical Depressive }\end{array}$ & .065 & .100 & .107 & \\
& Symptomatology & $.360^{*}$ & .140 & $.411^{*}$ & $.081^{*}$ \\
\hline
\end{tabular}

${ }^{*} p<.05 ;{ }^{* *} p<.01 ;{ }^{* * *} p<.001$ 


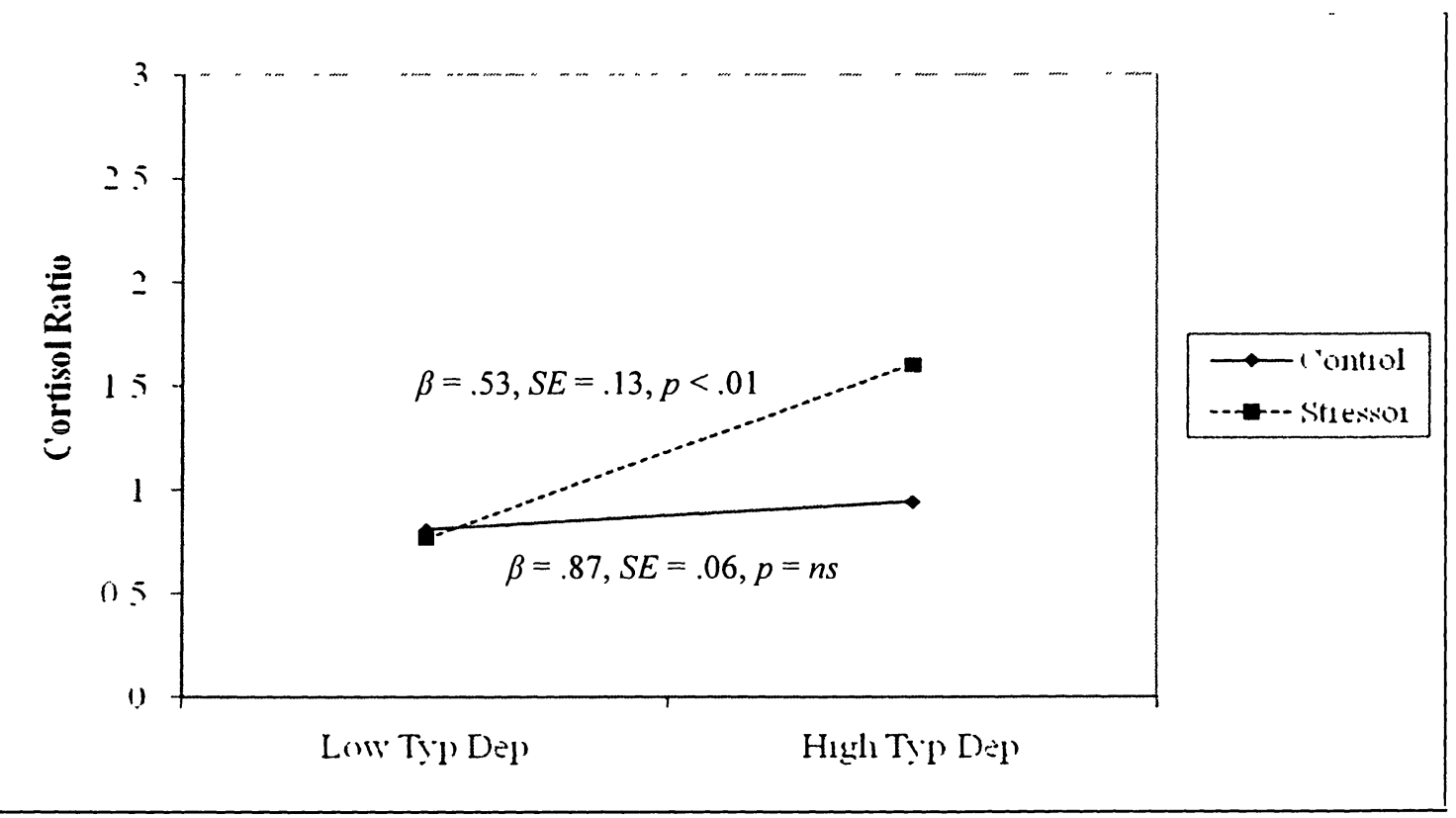

Figure 5. Hierarchical Regression lines showing the moderating effect of Condition (Stressor vs. Control) on the Relation between Typical Depressive Symptomatology (Total Scores on Beck Depression Inventory) and Cortisol Ratio scores (10-min posttask: Baseline) ${ }^{1}$.

Overall, it appeared that irrespective of stressor or control condition, emotional eating was related to greater feelings of shame, as well as increased food craving. Food craving for sugar and carbohydrates by emotional eaters measured immediately after the stressor was mediated by anticipation of relief, whereas after 20 -minutes this relation was found to be mediated by the anticipation of positive reinforcement that may result from eating. Craving for sweets was also driven by a preference for eating sweets in general. Emotional eating was not related to cortisol reactivity; however, increased typical

\footnotetext{
'Because ratio scores are subject to large variations based on the baseline cortisol level, a separate analysis was conducted using difference scores from baseline. This analysis yielded still stronger results relative to those obtained using ratio scores. $\left(R^{2}=.544, R^{2}\right.$ change $\left.=.054^{*}\right)$
} 
depressive symptomatology was related to increases of cortisol in response to the selfevaluative stressor.

\section{Discussion}

Responses to stressors and susceptibility to physical and mental health disturbances can differ depending on the type of stressor encountered and characteristics of the individual (Anisman \& Matheson, 2005) as well as the specific emotional responses that accompany the stressor (Dickerson \& Kemeny, 2004). The present investigation assessed whether emotional eating and depressive symptomatology were associated with responses to a self-evaluative stressor, such as shame, as well as anxiety, food craving, and cortisol levels. Although emotional eating was not related to different emotional or physiological outcomes in response to the stressor, emotional eating was related to greater feelings of shame and food craving. Furthermore, although emotional eating was not tied to changes of cortisol associated with the anticipatory stress, it appeared that depressive symptomatology was related to increased cortisol reactivity in response to the stressor. Specifically, typical depressive symptomatology was associated with increases of cortisol in the stressor condition, whereas atypical symptomatology was not significantly related to cortisol reactivity.

\section{Anxiety and shame in response to a self-evaluative stressor}

The stressor condition comprised the anticipation of performing a speech and mental math task in front of a panel of judges (Trier Social Stress Test), which has been found to elicit negative emotions, particularly shame, as well as decreased social self- 
esteem (Gruenewald, Kemeny, Aziz, \& Fahey, 2004). As emotional eaters have high levels of self-awareness and overeat particularly in response to self-evaluative stressors (Heatherton \& Baumeister, 1991, 1994), it was hypothesized that emotional eating would be associated with higher levels of shame and anxiety in response to the stressor condition.

The stressor was found to elicit significant increases in anxiety; however this was not influenced by emotional eating status. Emotional eating was related to higher levels of shame post-task, but this was apparent irrespective of stressor or control condition. These findings suggest that emotional eaters may tend to experience higher levels of shame, in general, or that the experimental setting itself was responsible for eliciting shame to a greater degree in emotional than in non-emotional eaters. In this regard, binge eating, which is strongly associated with emotional eating, has indeed been associated with greater fluctuations in self-esteem, negative affect, shame and guilt (Sanftner \& Crowther, 1998). Yet, another possibility is that a different component of the study, other than the experimental stressor, provoked feelings of shame in those with high emotional eating scores. All participants completed questionnaires regarding eating behaviors prior to being exposed to the control or stressor task, and it is possible that in the case of emotional eaters, having to report their maladaptive eating behaviors may have elicited feelings of shame.

Interestingly, when examining shame difference scores $(20$-min post-task baseline), emotional eating was related to a decrease in shame over the 20 -minute period, specifically in the stressor condition. As previously reported, emotional eating was related to higher shame scores immediately post-task in both stressor and control 
conditions. Therefore, the decrease in feelings of shame over the 20 -minute period, could be indicative of relief experienced over time, whereas low emotional eating was associated with low baseline shame scores to begin with, not allowing for much of a decrease.

\section{Food Craving}

Relationships between Food Preferences and Food Cravings. It was of interest to determine whether specific food cravings were consistent with reported food preferences. In general, preference for sweet foods was related to increased craving for sweets posttask and preference for meat was related to craving high-fat foods post-task. This consistency between preference and cravings was not found for carbohydrate-rich foods. However, this could be due to the classification of foods into carbohydrate, sweet, and high-fat groups. The foods classified as carbohydrate are high in carbohydrates, but not sweet, and mostly low in fat (e.g., rolls, biscuits, pasta, and rice); whereas, most foods in the sweet category comprised a combination of sugar, carbohydrates, and fat (e.g., brownies, cookies, and donuts). Therefore, it is more likely that it was the combination of sugar, carbohydrates and fat that was craved, rather than only one particular macronutrient. Indeed, the types of food that are most often craved are high-carbohydrate foods that are high in sugar and fat (Drewnowski, Kurth, Holden-Witse, \& Saari, 1992).

Emotional eating was related to craving sweets immediately post-task and craving both sweets and carbohydrates 20-minutes later. Interestingly, food craving immediately post-task was driven by anticipation of relief from negative states as a result of eating; whereas, craving reported 20 -minutes post-task was driven by anticipation of positive 
reinforcement that may result from eating. These results suggest that food craving is activated in emotional eaters when a situation provokes negative emotions (e.g., shame) because they anticipate that eating the food they crave will relieve them of the negative feelings experienced (e.g., "If I were to eat what I'm desiring, I am sure my mood would improve"). However, as negative feelings decrease over time (as seen with shame difference scores in the present study), food craving is no longer driven by anticipation of relief, but rather by anticipation of positive reinforcement (e.g., "Eating something tasty would feel wonderful").

Positive and negative reinforcement have also been described as factors central to alcohol and drug craving and addiction (Koob, \& Le Moal, 2005; Drummond, 2001). Indeed, there are common neurochemical (endogenous opiates and dopamine) reward pathways, brain regions, and conditioned behaviors that have been reported to be associated with both drug addiction and food craving and obesity (Johnson \& Kenny, 2010; Pelchat, 2002, 2009), and the terms "relief craving" and "reward craving" are often described as being central to the conceptualization of alcohol addiction (Heinz et al., 2003; Verheul, Van den Brink, \& Geerlings, 1999). In the case of drug addiction, taking the substance can lead to negative reinforcement by both acting as a form of escape and relief of negative mood, as well as by reducing withdrawal symptoms, thus perpetuating the cycle of abuse. Interestingly, comorbidity between drug and alcohol abuse and excessive preference and/or craving for sweets has also been reported (Pelchat, 2002), raising the possibility that these outcomes might involve overlapping neural circuitry. The present study assesses negative reinforcement induced by eating in the form of relief from negative emotions; however, there have been studies using animal models, which 
provide evidence that relief from withdrawal symptoms may also be a motivator in the case of excessive food (specifically sugar) intake (Colantuoni et al., 2002). A review by Avena, Rada, \& Hoebel (2008) supports the perspective that intermittent, excessive access to sugar in rats can provoke behavioural and neurochemical changes consistent with those associated with drug and alcohol abuse in humans, particularly processes involving the dopamine-reward system (Wang et al., 2001) as well as opioid peptides in the case of binge eating (Drewnowski, Krahnm Demitrack, Nairn, \& Gosnell (1992). Further to this issue, it was recently reported that when rats were placed on a high fat diet, the subsequently displayed compulsive attraction to this food was highly resistant to change. This behavioral profile was accompanied by a down regulation of $\mathrm{D} 2$ receptors within the striatum, just as observed in some instances of drug addictions, essentially suggesting that greater consumption of the desired food was necessary to maintain its rewarding value (Johnson \& Kenny, 2010).

Taken together, these finding provide evidence that food can be addictive, especially high sugar foods, and that "food addiction" and craving seem to be mediated by the same neurochemical pathways and psychological processes (desire for positive and negative reinforcement) as drug and alcohol addiction.

\section{Cortisol Reactivity to the Stressor and in relation to depression}

Emotional Eating. Earlier research had indicated that high cortisol reactivity was associated with increased snacking, hunger, binge eating and increased intake of calories from fat in response to stressors, and that emotional eating served as a potential moderator in this regard (Epel, Lapidus, McEwen, \& Brownell , 2001; Gluck, Geliebter, 
Hung, \& Yahav, 2004; Newman, O’Conor, \& Conner, 2007). In the present investigation it was expected that emotional eating would be related to high cortisol reactivity in response to the stressor. However, there was no significant association between emotional eating and cortisol levels.

Inasmuch as increased HPA activity has been associated with major depressive disorder (e.g., Nemeroff, 1996), and that individuals high in depression might be particularly stress reactive, it was hypothesized that depressive symptomatology would be positively related to cortisol reactivity to a self-evaluative stressor. Separate analyses were conducted for typical and atypical depressive symptoms. Measures of cortisol at baseline (immediately before introduction to the stressor task) and 25-minutes later (10minutes post-completion of the task) indicated that typical depressive symptomatology (total score on the BDI) was related to an increase of cortisol in response to the stressor.

Due to the fact that a feature of atypical depression is that of high emotional reactivity, it was expected that atypical symptomatology might be more closely tied to changes of cortisol levels than typical symptomatology. However, atypical symptomatology was not significantly related to cortisol reactivity to the stressor. This is in line with evidence that atypical depression is associated with cortisol hypoactivity due to a down-regulated HPA-axis and CRH deficiency (Anisman, Ravindran, Griffiths, \& Merali, 1999; Gold, \& Chrousos, 2002).

Whereas, aty்pical depression has been associated with cortisol hypoactivity, there is much evidence linking typical major depression, and particularly melancholia, with cortisol hyperactivity and an altered feedback inhibition of cortisol (Maes, Bosmans, Meltzer, Scharpe, \& Suy, 1993; Zunszain, Anacker, Cattaneo, Carvalho, \& Pariante, 
2010). However, there have been conflicting results regarding acute cortisol reactivity in response to stressors among depressed individuals, including reports of increased, normal, and blunted cortisol responses. (Burke, Davis, Otte, \& Mohr, 2006; Zunszain et al, 2010). Of note, is that the majority of studies did not specify whether samples consisted of participants with typical, atypical, or a combination of features. In a metaanalysis of seven studies investigating plasma cortisol responses of MD patients to selfevaluative social stressors, Burke, Davis, Otte, \& Mohr (2006) reported normal or blunted cortisol reactivity. Hypercortisolism and impaired recovery were also observed. This pattern of blunted cortisol reactivity and impaired recovery was positively related to age and severity of depression, but once again typical vs. atypical symptoms did not factor into the analysis.

It is important to differentiate studies using clinical samples of patients with MD, from the present study, which assessed the relationship between cortisol reactivity and depressive symptomatology in a student sample of which $68 \%$ were below the clinical threshold for depression according to BDI scores. In a sample of young healthy men in the non-clinical range of depression, levels of depressive symptomatology were positively related to basal cortisol levels, as well as measures of chronic and acute stress perception (Pruessner, Hellhammer, Pruessner, \& Lupien, 1996). There have also been studies of non-clinical samples investigating susceptibility to depression in response to stressful life events, specifically the relationship between cortisol reactivity and the polymorphism in the promoter region of the serotonin transport gene (5-HTTLPR). Individuals homozygous for the short $(s)$ allele, which has been associated with higher rates of depression and other psychiatric disorders, have shown greater and more 
prolonged cortisol reactivity in response to the self-evaluative stressors in a sample of girls aged 9-14 (Gotlib, Joormann, Minor, \& Hallmayer, 2008), as well as men (Alexander et al., 2009).

Taken together with these findings, the present results suggest that high cortisol reactivity in response to stressors (in this case self-evaluative stressors) is associated with increased depressive symptoms. Dickerson, Gruenewald, \& Kemeny (2004) reported that cortisol, feelings of shame and decreased social self-esteem are activated in concert by social self threats, such as the Trier Social Stress Test, and that negative selfevaluation is central to shame. Because negative self-esteem is a risk factor for depression (Cheng \& Furnham, 2002; Evans, Heron, Lewis, Araya, \& Wolke, 2005), and can be activated by stressful or schema-congruent events and mildly depressed mood (Roberts \& Monroe, 2002) it was expected that depressive symptomatology would be associated with increased feelings of shame activated by the self-evaluative stressor, which would be accompanied by greater cortisol reactivity. However, feelings of shame reported immediately post-task were not related to typical or atypical depressive symptomatology.

It is possible that the self-evaluative stressor did indeed activate thoughts and feelings related to lower self-esteem and shame, but that the measure of shame used in the present study (adjectives from the PANAS including ashamed, embarrassed, humiliated) was not sufficiently sensitive to capture this emotion. The addition of specific shame measures such as, the Test of Self-Conscious Affect (measure of shame proneness), The Experience of Shame Scale (measure of shame related to self and performance) and the Shame subscale of the State Shame and Guilt Scale, might be more 
effective in tapping into state emotions of shame, as well as the propensity towards feeling these emotions.

\section{Conclusions and Limitations}

There are several limitations of the present investigation that need to be underscored. The sample consisted of female undergraduate students, thus limiting the population to which the results might be applicable. A female sample was used because emotional eating is reported more often in women, and this group has a tendency to consume more calories, fat, sugar, and snack foods in response to stressors (McCann, Warnick, \& Knopp, 1990; Wardle, Steptoe, Oliver, \& Lipsey, 2000). Still, emotional eating does occur in males and it may be necessary to determine whether their responses are comparable to those evident in women.

As previously mentioned, the present study did not involve a clinical sample; therefore, the conclusions drawn regarding depressive symptomatology were derived from a sample whose mean total BDI scores were low. Thus, the present data do not speak to vulnerabilities or cortisol reactivity that might be related to clinical levels of depression.

As is necessary with any study of stress in a laboratory context, the effectiveness of the stressor needs to be considered. The Trier Social Stress Test is a commonly used psychological stressor that has been reported to provoke cortisol reactivity and feelings of shame (Dickerson, Gruenewald, \& Kemeny, 2004). However, the present investigation used only the anticipation period of the stressor to evaluate whether the manipulation was effective as a stressor, without participants actually having to perform the speech and arithmetic task. As reported, we found that the stressor condition moderated the 
relationship between typical depressive symptomatology and cortisol reactivity.

However, if the evaluative component of the TSST had been included (participants had to perform the speech and mental math task in front of a panel of judges), greater differences in reported emotions and cortisol reactivity may have been observed between stressor and control groups, particularly if shame related to the actual performance was an element that contributed to the cortisol changes.

Another limitation of the present study concerned measurements of emotions in response to the stressor. Participants completed the Positive Affect Negative Affect Scale (PANAS) immediately after the 15-min anticipation period. However, they were first told that they would no longer have to perform the speech they had been preparing. Although participants were told to complete the PANAS questionnaire according to how they felt before they had been told they no longer had to give the speech, the measure may have been more accurate if they had completed it while still anticipating having to do the task. Also as previously mentioned, the use of other mood questionnaires in addition to the adjective measures on the PANAS may have better tapped into emotions experienced by participants.

There are potential disadvantages that are inherent in using explicit self-report measures. All variables in the study were measured by participant completion of questionnaires. Thus, the answers to questions could have been influenced by wording, order, and most importantly, socially desirable response tendencies. For this reason, we conducted a preliminary study (Study 2) including an implicit measure of attitudes regarding various types of food; however, the measure was not sufficiently sensitive to differentiate between emotional and non-emotional eaters and stressor/control conditions. 
Perhaps the measure would have been more effective in a different context, such as exposure to a stressor that was related to food and eating in some way, thus activating emotions specific to the food-related attitudes we were trying to measure. Indeed, implicit attitudes measured by the Affective Priming Paradigm (used in the Study 2) can be influenced by the nature of the experimental context (De Houwer, Teige-Mocigemba, Spruyt, \& Moors, 2009). Therefore, some attitudes may only be activated by particular conditions, which could have been the case in Study 2 .

The present study measured relations between food cravings and reported emotional eating behavior; however, actual eating behavior in the laboratory environment was not measured. There are potential problems associated with measuring eating in a laboratory environment, such as food consumption being highly affected by the choice of food(s) offered (Oliver, Wardle, \& Gibson, 2000; Wallis \& Hetherington, 2009). However, it is important to evaluate whether the reported food cravings for carbohydrates and sugar would reliably predict food consumption, and whether having actual access to food would have affected the psychological factors related to craving (anticipation of positive and negative reinforcement). There have been several laboratory studies examining eating in response to stressors; however, it would be important to combine behavior and food craving measures to evaluate their consistency, as food craving has been reported to drive overeating (Hill, Weaver, \& Blundell, 1991; Mercer \& Holder, 1997). In this regard, it was reported that participants indicated that they indulged their food cravings at least half the time (Weingarten, \& Elston, 1991), and as such it seems that food craving is a reliable, but not a guaranteed predictor of food consumption. 
Despite the limitations described, the present investigation provided several interesting findings regarding emotional eating, craving, stress, and depressive symptoms. Among other things, emotional eating status was related to increased feelings of shame immediately post-task; however, this result was not specific to the stressor condition. Therefore, it is still unclear as to what provoked feelings of shame in emotional eaters, and whether feelings of shame were related to eating behaviour.

The study helped to elucidate the various psychological factors underlying specific food craving in emotional eaters, providing support for the food addiction hypothesis. These findings combined with those reporting neurochemical and neurophysiological changes related to food addiction can help to inform cognitivebehavioral, and/or pharmacological treatment for chronic food cravings, emotional eating, and binge eating. Future research in human food addiction should evaluate the impact of treatment on the psychological factors associated with craving as well as on underlying neurochemistry.

Clear differences were also reported between typical and atypical depressive symptomatology and the relationship to cortisol reactivity in a non-clinical sample. It may be fruitful to continue to elucidate the differences between cross sectional specifiers of major depression (including melancholic, atypical, post-partum) at different levels of severity and their relationship to stress reactivity. The present investigation found a link between high cortisol reactivity and typical depressive symptoms, supporting the perspective that cortisol reactivity could be a marker for risk of depression. 


\section{References}

Anisman, H., \& Zacharko, M. (1982). Depression: The predisposing influence of stress. Behavioral and Brain Sciences, 5(1), 89-137.

Agras \& Telch. (1998). The effects of caloric deprivation and negative affect on binge eating in obese binge-eating disordered women. Behavior Therapy, 29 (3), 491 503.

Alexander, N., Kuepper, Y., Schmitz, A., Osinsky, R., Kozyra, E., \& Hennig J. (2009). Psychoneuroendocrinology, 34(9), 1294-1303.

American Psychiatric Association. (2000). Diagnostic and statistical manual of mental disorders (4th ed., text revision). Washington, DC: Author.

Anderson K. E., Rosner W., Khan, M.S., New, M. I., Pang, S., Wissel, P. S. and Kappas, A. (1987). Diet-hormone interactions: protein/carbohydrate ratio alters reciprocally the plasma levels of testosterone and cortisol and their respective binding globulins in man. Life Sciences, 40, 1761-1768.

Anisman, H., Matheson, K.: Stress, depression, and anhedonia: caveats concerning animal models. (2005) Neurosci Biobehav Rev, 29, 525-546.

Anisman, H., Ravindran, A.V., Griffiths, J., \& Merali, Z. (1999). Endocrine and cytokine correlates of major depression and dysthymia with typical or atypical features. Molecular Psychiatry, 4, 182-188.

Antony, M. M., Johnson, W. G., Carr-Nangle, R. E., \& Abel, J. L. (1994). Psychopathology correlates of binge eating and binge eating disorder. Comprehensive Psychiatry, 35(5), 386-392.

Avena, N.M., Rada, P., \& Hoebel, B.G. (2008). Evidence for sugar addiction: behavioral and neurochemical effects of intermittent excessive sugar intake. Neurosci Biobehav Rev., 32(1), 20-39.

Ball, K.. \& Lee, C. (2002). Psychological stress, coping, and symptoms of disordered eating in a community sample of young Australian women. International Journal of Eating Disorders, 31, 71-81.

Barnes, L.L., Harp, D., \& Jung, W. S. (2002). Reliability Generalization of Scores on the Spielberger State-Trait Anxiety Inventory. Educational and Psychological Measurement, 62 (4), 603-618. 
Beck, A.T., Ward, C.H., Mendelson, M., Mock, J., Erbaugh, J. (1961). An inventory for measuring depression. Archives of General Psychiatry, 4, 561-569.

Bellezza, F. S., Greenwald, A. G., \& Banaji, M. R. (1986). Words high and low in pleasantness as rated by male and female college students. Behavior Research Methods, Instruments, and Computers, 18, 299-303.

Bellisle, F., Louis-Sylvestre, J., Linet, N., Rocaboy, B., Dalle, B., Cheneau, F., L'Hinoret, D., \& Guyot, L. (1990). Anxiety and food intake in men. Psychosomatic Medicine, 52, 452-457.

Biondi, M, \& Picardi, A. (1999). Psychological stress and neuroendocrine functioning humans: the last two decades of research. Psychotherapy Psychosomatics. 68, 144-150.

Blum, K., Braverman, E. R., Holder, J. M., Lubar, J. F., Monastra,V. J., Miller, D., Lubar, J. O., Chen, T. J. \& Comings, D. E. (2000). Reward deficiency syndrome: a biogenetic model for the diagnosis and treatment of impulsive, addictive, and compulsive behaviours. Journal of Psychoactive Drugs, 32, 1-112.

Bohon, C., Stice, E., \& Spoor, S. (2009). Female Emotional Eaters Show Abnormalities in Consummatory and Anticipatory Food Reward: A Functional Magnetic Resonance Imaging Study, International Journal of Eating Disorders, 42, 210221.

Bohon, C., Stice E., Spoor, S. (2009). Female Emotional Eaters Show Abnormalities in Consummatory and Anticipatory Food Reward: A Functional Magnetic Resonance Imaging Study. The International journal of eating disorders, 42(3), 210-221.

Brown, G.W., Bifulco, A. \& Harris, T. O. (1987). Life events, vulnerability and onset of depression: some refinements. British Journal of Psychiatry, 150, 30-42.

Bruch H. (1964). Psychological Aspects of Overeating And Obesity. Psychosomatics 5, 269

Bruch, H. (1973). Psychiatric aspects of obesity. Psychiatric Annals, 3, 6-10.

Burke H.M., Davis M.C., Otte C. and Mohr D.C. (2006). Depression and cortisol responses to psychological stress: A meta-analysis, Psychoneuroendocrinology, $30,846-856$. 
Burton P., Smit H. J., Lightowler H. J. (2007). The influence of restrained and external eating patterns on overeating. Appetite 49:191-197.

Cannon, W. B. (1915). Bodily changes in pain, hunger, fear and rage $\left(2^{\text {nd }}\right.$ ed. New York: Appleton.

Carlson, A. J., (1916). The control of hunger in health and disease. Chicago: University of Chicago Press.

Chen, W.-Q.. Siu, O.-L., Lu, J.-F., Cooper, C. L.. \& Phillips, D. R. (2009). Work stress and depression: the direct and moderating effects of informal social support and coping. Stress and Health, 25(5), 431-443.

Cheng, H., \& Furnham, A. (2002). Personality, peer relations, and self-confidence as predictors of happiness and loneliness, Journal of Adolescence, 25(3), 327-339.

Christensen L, Somers S. (1996). Comparison of nutrient intake among depressed and non-depressed individuals. International Journal of Eating Disorders. 20, 105109.

Christensen L. (2001). The effect of food intake on mood. Clinical Nutrition, 20, 161166.

Cohen, S., Kamarck, T., \& Mermelstein, R. (1983) A Global Measure of Perceived Stress. Journal of Health and Social Behavior, 24, 385-396.

Colantuoni C., Rada P., McCarthy J., Patten C., Avena N.M., Chadeayne A., Hoebel B.G. (2002). Evidence that intermittent, excessive sugar intake causes endogenous opioid dependence. Obesity Research, 10(6) 478-88.

Cools, J. Schotte, D. E., \& McNally, R.J. (1992). Emotional arousal and overeating in restrained eaters. Journal of Abnormal Psychology, 101, 348-351.

Craeynest, M., Crombez, G., De Houwer, J., Deforche, B., Tanghe, A., \& De Bourdeaudhuij, I. (2005). Explicit and implicit attitudes towards food and physical activity in childhood obesity. Behaviour Research and Therapy, 43, $1111-1120$.

Czyzewska, M. \& Graham, R. (2008). Implicit and explicit attitudes to high- and low calorie food in females with different BMI status. Eating Behaviors, 9(3), 303312 .

Dallman M. F., Pecoraro N., Akana S. F., la Fleur S. E., Gomez F., Houshyar H., Bell M. E., Bhatnagar S., Lauger K. D., Manalo S. (2003) Chronic stress and obesity: a new view of "comfort food". Brain, Behavior, \& Immunity, 100, 11696-701. 
Dallman, M. F. (2010) Stress-induced obesity and the emotional nervous system. Trends in Endocrinology and Metabolism, 21(3), 159-165.

de Castro J.M. (1987). Macronutrient relationships with meal patterns and mood in the spontaneous feeding behaviour of humans. Physiology and Behavior, 39, 561-9.

De Houwer, J.. Teige-Mocigemba, S.. Spruyt, A.. \& Moors, A. (2009). Implicit measures: A normative analysis and review. Psychological Bulletin. 135. 347368.

de Lauzon-Guillain B., Romon, M. Musher-Eizenman, D., Heude, B., Basdevant, A., Charles, M.A., \& the Fleurbaix-Laventie Ville Santé Study Group. (2008). Cognitive restraint, uncontrolled eating and emotional eating: correlations between parent and adolescent. Maternal and Child Nutrition, 5(2), 171-178.

Denisoff, E., \& Endler, N. S. (2000). Life experiences, coping, and weight preoccupation in young adult women. Canadian Journal of Behavioural Science, 32(2), 97-103.

deZwaan, M., Mitchell, J. E., Seim, H. C., Specker, S. M., Pyle, R. L., Raymond, N. C., Crosby, R. B. (1994). Eating related and general psychopathology in obese females with binge eating disorder. International Journal of Eating Disorders, 15, 43-52.

Dickerson, S. S., Gruenewald, T. L., \& Kemeny, M. E. (2004). When the Social Self Is Threatened: Shame, Physiology, and Health. Journal of Personality, 72(6), 11911216.

Dickerson, S. S., \& Kemeny, M. E. (2004). Acute stressors and cortisol responses: A theoretical integration and synthesis of laboratory research. Psychological Bulletin, 130(3), 355-391.

Drewnowski, A., Krahn, D. D., Demitrack, M. A., Nairn, K. \& Gosnell, B. A. (1992) Taste responses and preferences for sweet high-fat foods: evidence for opioid involvement. Physiology and Behavior, 51, 371-379.

Drewnowski, A., Kurth, C., Holden-Wiltse J., \& Saari, J. (1992). Food preferences in human obesity: carbohydrates versus fats. Appetite, 18(3), 207-21.

Drummond, D.C. (2001). Theories of drug craving, ancient and modern. Addiction, 96(1), 33-46.

Eldredge, K.L., \& Agras, W.S. (1996). Weight and shape overconcern and emotional eating in binge eating disorder. International Journal of Eating Disorders, 19, 7382. 
Elmore, D. K. \& de Castro, J. M. (1991) Meal patterns of normal, untreated bulimia nervosa and recovered bulimic women. Physiology and Behavior, 49:99-105.

Epel, E., Lapidus, R., McEwen, B. \& Brownell, K. (2001). Stress may add bite to appetite in women: A laboratory study of stress-induced cortisol and eating behaviour. Psychoneuroendocrinology, 26, 37-49.

Evans, J., Heron, J. Lewis, G., Araya, R., \& Wolke, D. (2005). Negative self-schemas and the onset of depression in women: longitudinal study, The British Journal of Psychiatry, 186, 302-307.

Fazio RH, Olson MA. 2003. Implicit measures in social cognition research: their meaning and uses. Annu. Rev. Psychol. 54:297-327.

Fedoroff, I. C., Polivy, J., \& Herman, C. P. (2003). The specificity of restrained versus unrestrained eaters' responses to food cues: general desire to eat, or craving for the cued food? Appetite, 41, 7-13.

Fernstrom J. D., \& Wurtman R. J. (1971). Brain serotonin content: increase following ingestion of carbohydrate diet. Science, 17, 1023-1025.

Fernstrom J. D., \& Wurtman R. J. (1972). Brain serotonin content: physiological regulation by plasma neutral amino acids. Science, 178, 414-416.

Fernstrom M. H., Krowinski R.L., Kupfer D. J. Appetite and food preference in depression: effects of imipramine treatment. (1987). Biological Psychiatry, 22, 529-39.

Fernstrom, J. D. (1988) Tryptophan, Serotonin and Carbohydrate Appetite: Will the Real Carbohydrate Craver Please Stand Up! The Journal of Nutrition, 118, 1417-1419.

Fernstrom, M. H., \& Fernstrom, J. D. (1995) Brain tryptophan concentrations and serotonin synthesis remain responsive to food consumption after the ingestion of sequential meals. The American journal of clinical nutrition, 61(2), 407S-448.

Fitzgibbon, M. L. \& Kirschenbaum, D.S. (1990). Heterogeneity of clinical presentation among obese individuals seeking treatment. Addictive Behaviors, 15, 291-295.

Foster M. T., Solomon M. B., Huhman K. L., Bartness T. J. (2006). Social defeat increases food intake, body mass, and adiposity in Syrian hamsters. American Journal of Physiology Regulatory, Integrative and Comparative Physiology, 290.

Franken, I. H. A., \& Muris P. (2005). Individual differences in reward sensitivity are related to food craving and relative body weight in healthy women. Appetite, 45, 198-201. 
Freeman L. M., Gil K. M. (2004). Daily stress, coping, and dietary restraint in binge eating. International Journal of Eating Disorders, 36, 204-212.

Frost, R. O., Goolkasian, G. A., Ely, R. J., \& Blanchard, F. A. (1982).

Depression, restraint, and eating behavior. Behaviour Research and Therapy, 20, 113-121.

Gendall, Joyce, Sullivan, \& Bulik, 1998; Gendall, K. A., Joyce, P. R., Sullivan, P. F., \& Bulik, C. M. (1998). Food cravers: Characteristics of those who binge. International Journal of Eating Disorders, 23, 353-360.

Gluck, M. E., Geliebter, A., Hung, J., \& Yahav, E. (2004). Cortisol, Hunger, and Desire to Binge Eat Following a Cold Stress Test in Obese Women With Binge Eating Disorder. Psychosomatic Medicine, 66, 876-881.

Gold P. W., Chrousos G. P. (2002). Organization of the stress system and its dysregulation in melancholic and atypical depression: high $v s$. low CRH/NE states. Molecular Psychiatry, 7, 254-275.

Goossens, L., Braet, L., Van Vlierberghe, S., \& Mels, S. (2009). Weight parameters and pathological eating as predictors of obesity treatment outcome in children and adolescents. Eating Behaviors, 10(1), 71-73.

Gotlib, I.H., Joormann, J., Minor, K. L, \& Hallmayer, J. (1996). HPA-Axis Reactivity: A Mechanism Underlying the Associations Among 5-HTTLPR, Stress, and Depression. Biological Psychiatry, 63 (9) 847-851.

Greeno, C. G., \& Wing, R. R. (1994). Stress-induced eating. Psych Bull. 115, 444-464.

Gruenewald, T. L., Kemeny, M. E., Aziz, N., \& Fahey J. L. (2004). Acute threat to the social self: shame, social self-esteem, and cortisol activity. Psychosom Med., 66(6), 915-24.

Grunberg, N. E., \& Straub, R. O. (1992). The role of gender and taste class in the effects of stress on eating. Health Psychology, 11, 97-100.

Hammen, Brennan, Keenan-Miller, Hazel, \& Najman. (2010). Chronic and acute stress, gender, and serotonin transporter gene-environment interactions predicting depression symptoms in youth. Journal of Child Psychology and Psychiatry, 51(2), $180-187$.

Haynes, C., Lee, M. D., \& Yeomans, M. R. (2003). Interactive effects of stress, dietary restraint, and disinhibition on appetite. Eating Behaviors, 4(4), 369-383. 
Heatherton T. F., Baumeister R. F. (1991). Binge eating as escape from self-awareness. (1991). Psych Bull, 119, 86-108.

Heatherton, T. F., Herman, C. P., \& Polivy, J. (1991). Effects of physical threat and ego threat on eating behaviour. Journal of Personality and Social Psychology, 60, 138-143.

Heatherton, T. F., Herman, C. P., \& Polivy, J. (1992). Effects of distress on eating: The importance of ego-involvement. Journal of Personality and Social Psychology. 62, 801-803.

Heinz, A., Lober, S., Georgi, A., Wrase, J., \& Hermann, D., Rey, E.-R., Wellek, S., \& Mann, K. (2003). Reward craving and withdrawal relief craving: assessment of different motivational pathways to alcohol intake. Alcohol and Alcoholism. 38(1), 35-39.

Hermans, D., De Houwer, J., \& Eelen, P. (1994). The affective priming effect: Automatic evaluation of evaluative information in memory. Cognition and Emotion, 8, 515 533.

Hill, A. J., Weaver, C. F. L., \& Blundell, J. E. (1991). Food craving, dietary restraint and mood. Appetite, 17, 177-185.

Johnson P. M., Kenny P. J. (2010). Dopamine D2 receptors in addiction-like reward dysfunction and compulsive eating in obese rats. Nature Neuroscience, Mar 28. [Epub ahead of print]

Kandiah J., Yake, M., \& Willett, H. (2008). Effects of stress on eating practices among adults. Family and Consumer Sciences Research Journal, 37(1), 27-38.

Kane, T. A., Loxton, N. J., Staiger, P. K., \& Dawe, S. (2004). Does the tendency to act impulsively underlie binge eating and alcohol use problems? An empirical investigation. Personality and Individual Differences, 36, 83-94.

Kaplan \& Kaplan, 1957 Kaplan, H. I., \& Kaplan, H. S. (1957). The psychosomatic concept of obesity. Journal of Nervous and Mental Disorders, 125, 181-201.

Keel, P. K., Mitchell, J. E., Miller, K. B., Davis, T. L., \& Crow, S. J. (2000). Predictive validity of bulimia nervosa. American Journal of Psychiatry, 157, 136-138.

Kendler, K. S., Karkowski, L. M. \& Prescott, C. A. (1999). Causal relationship between stressful life events and the onset of major depression. American Journal of Psychiatry, 156, 837-841. 
Kirschbaum C., Pirke K.-M., Hellhammer D. H. (1993). The "Trier Social Stress Test"a tool for investigating psychobiological stress responses in a laboratory setting. Neuropsychobiology, 28, 76-81.

Koff, E., \& Sangani, P. (1997). Effects on coping style and negative body image on eating disturbance. International Journal of Eating Disorders, 22(1), 51-56.

Koob, G.F, Le Moal, M. (2005). Plasticity of reward neurocircuitry and the 'dark side' of drug addiction. Nat. Neurosci ., 8, 1442-1444.

Kubiak, T., Vogele, C., Siering, M., Schiel, R., \& Weber, H. (2008). Daily hassles and emotional eating in obese adolescents under restricted dietary conditions-The role of ruminative thinking. Appetite, 51, 206-209.

Larsen J. K., van Strien T., Eisinga R., Engels R. C. (2006). Gender differences in the association between alexithymia and emotional eating in obese individuals. Journal of Psychosomatic Research, 60, 237-243.

Lazarus, R. S., \& Folkman, S. (1984). Stress, appraisal and coping. NewYork: Springer.

Lowe, M. R., \& Kral, T. V. (2006). Stress-induced eating in restrained eaters may not be caused by stress or restraint. Appetite, 46(1), 16-21.

Lyke, J. A., \& Spinella, M. (2004). Associations among aspects of impulsivity and eating factors in a nonclinical sample. International Journal of Eating Disorders, 36(2), $229-233$.

Lynch, W.C., Everingham, A., Dubitzky, J., Hartman, M., Kasser, T. (2000). Does binge eating play a role in the self-regulation of moods? Integrative Physiological and Behavioral Science, 35, 298-313.

Macht, M., \& Mueller, J. (2007). Immediate effects of chocolate on experimentally induced mood states. Appetite, 49, 667-674.

Maes, M., Bosmans, E., Meltzer, H.Y., Scharpe S., \& Suy, E. (1993). Interleukin-1 beta: a putative mediator of HPA axis hyperactivity in major depression? American Journal of Psychiatry, 150, 1189-1193.

Manzoni, G. M., Pagnini, F., Gorini A., Preziosa A., Castelnuovo, G., Molinari, E., \& Riva G. (2009). Can relaxation training reduce emotional eating in women with obesity? An exploratory study with 3 months of follow-up. Journal of the American Dietetic Association, 109(8), 1427-32.

Masheb, R. M., \& Grilo, C. M. (2006). Emotional Overeating and its Associations with Eating Disorder Psychopathology among Overweight Patients with Binge Eating Disorder. Journal of Eating Disorders, 39(2), 141-146. 
Matheson, K., Anisman, H. (2003). Systems of coping associated with dysphoria, anxiety, and depressive illness: A multivariate profile perspective. Stress, 6, 223234.

McCann, B. S., Warnick, G. R., Knopp, R. H. (1990). Changes in plasma lipids and dietary intake accompanying shifts in perceived workload and stress.

Psychosomatic Medicine, 52, 97-108.

Mercer, M., \& Holder, M. (1997). Food Cravings, Endogenous Opioid Peptides, and Food Intake: A Review, Appetite, 29(3), 352-352.

Muller, J., Dettmer, D., \& Macht, M. (2008). The Attitudes to Chocolate Questionnaire: psychometric properties and relationship to dimensions of eating. Appetite, 50(23), 499-505.

Nasser, J. A., Gluck, M. E., \& Geliebter, A. (2004). Impulsivity and test meal intake in obese binge eating women. Appetite, 43, 303-307.

Nederkoorn, C., Smulders, F. T. Y., Havermans, R. C., Roefs, A., \& Jansen, A. (2006). Impulsivity in obese women. Appetite, 47(2), 253-256.

Nemeroff, C.B. (1996) The corticotropin-releasing factor (CRF) hypothesis of

depression: New findings and new directions. Molecular Psychiatry, 1, 336-342.

Newman, E., O'Connor, D. B., \& Conner, M. (2007). Daily hassles and eating behaviour: The role of cortisol reactivity. Psychoneuroendocrinology, 32, 125-132.

Nierenberg A. A., Alpert J. E., Pava J., Rosenbaum J. F., Fava M.(1999). Course and treatment of atypical depression. Journal of Clinical Psychiatry. 59(suppl 18), 59.

Nijs, I. M. T., Franken, I. H. A., Muris, P. (2007). The modified Trait and State FoodCravings Questionnaires: Development and validation of a general index of food craving. Appetite, 4, 38-46.

Nolen-Hoeksema, S. (1991). Responses to depression and their effects on the duration of depressive episodes. Journal of Abnormal Psychology, 100, 569-582.

Nolen-Hoeksema, S., \& Morrow, J. (1991). A Prospective Study of Depression and Posttraumatic Stress Symptoms After a Natural Disaster: The 1989 Loma Prieta Earthquake. Journal of Personality and Social Psychology, 61(1), 115-121.

Nolen-Hoeksema, S., Morrow, J., \& Fredrickson, B. L. (1993). Response Styles and the Duration of Episodes of Depressed Mood. Journal of Abnormal Psychology, 102(1), 20-28. 
Nolen-Hoeksema, S. (1998). The other end of the continuum: The costs of rumination. Psychological Inquiry, 9(3), 216-219.

O’Connor, D. B., Jones, F., Conner, M., McMillan, B., \& Ferguson, E. (2008). Effects of Daily Hassles and Eating Style on Behavior, Health Psychology, 27(1), S20-31.

O’Connor, D. B., O'Connor, R. C., \& Marshall, R. (2007). Perfectionism and psychological distress: Evidence of the mediating effects of rumination. European Journal of Personality, 21, 429-452.

Oliver G., Wardle J., Gibson E. L. (2000). Stress and food choice: a laboratory study. Psychosomatic Medicine, 62, 853-865.

Oliver, G., \& Wardle, J. Perceived effects of stress of food choice (1999). Physiology \& Behavior, 66, 511-515.

Ouwens, M., van Strien, T. \& van Leeuwe, J. (2009). Possible pathways between depression, emotional and external eating. A structural equation model. Appetite, 53(2), 245-248.

Papies, E. K., Stroebe, W., \& Aarts, H. (2009). Who likes it more? Restrained eaters' implicit attitudes towards food, Appetite, 53, 279-287.

Patel, S. R., Malhotra, A., White, D. P., Gottlieb, D. J., \& Hu, F. B. (2006). Association between Reduced Sleep and Weight Gain in Women. American Journal of Epidemiology, 164, 947-954.

Patton, J. H., Stanford, M. S., \& Barratt. (1995). Factor Structure of the Barratt Impulsiveness Scale. Journal of clinical psychology, 51(6), 768-774.

Paxton \& Diggens, 1997; Paxton, S. J., \& Diggens, J. (1997.), Avoidance coping, binge eating, and depression: An examination of the escape theory of binge eating. International Journal of Eating Disorders, 22: 83-87.

Peacock, M. A., \& Wong, P. T. P. (1990) The stress appraisal measure (SAM): A multidimensional approach to cognitive appraisal. Stress Medicine. 6(3), 227-236.

Pelchat, M. (2002) Of Human Bondage: Food Craving, Obsession, Compulsion and Addiction. Physiology and Behavior, 76: 347-352.

Pelchat, M. L. (2009) Food Addiction in Humans. Journal of Nutrition, 139(3), 620-622.

Pellegrin K. L., O'Neil P. M., Stellefson E. J., Fossey M. D., Ballenger, J. C., Cochrane C. E., \& Currey H. S. (1998). Average daily nutrient intake and mood among obese women. Nutrition Research, 18, 1103-12. 
Peñas-Lledó E., Vaz F. J., Ramos M.I., Waller G. (2002). Impulsive behaviors in bulimic patients: relation to general psychopathology. International Journal of Eating Disorders, 32(1), 98-102.

Polivy J., Herman C. P., \& McFarlane (1994). Effects of anxiety on eating: does palatability moderate distress-induced overeating in dieters? Journal of Abnormal Psychology, 103, 505-10.

Polivy, J., \& Herman, P. (1999). Distress and eating: Why do dieters overeat? International Journal of Eating Disorders, 26, 153-164.

Pollard, T. M., Steptoe, A., Canaan, L., Davies, G. J., \& Wardle, J. (1995).The effects of academic examination stress on eating behaviour and blood lipid levels. International Journal of Behavioral Medicine, 2, 299-320.

Preacher, \& Hayes (2004). SPSS and SAS procedures for estimating indirect effects in simple mediation models. Behavior Research Methods, Instruments, \& Computers, 36(4), 717-731.

Preacher, K. J., \& Hayes, A. F. (2008). Asymptotic and resampling strategies for assessing and comparing indirect effects in multiple mediator models. Behavior Research Methods, 40, 879-891.

Pruessner, M., Hellhammer, D.H., Pruessner, J. C., \& Lupien, S. J. (2003) Self-Reported Depressive Symptoms and Stress Levels in Healthy Young Men: Associations With the Cortisol Response to Awakening Psychosomatic Medicine 65, 92-99.

Quinton, S., \& Wagner, H. L. (2005). Alexithymia, ambivalence over emotional expression, and eating attitudes. Personality and Individual Differences, 38(5), 1163-1173.

Roefs A., Herman C. P., MacLeod C. M., Smulders F. T., Jansen A. (2005). At first sight: how do restrained eaters evaluate high-fat palatable foods? Appetite. 44, 103-114.

Roefs, Werrij, Smulders, \& Jansen. (2006). The Value of Indirect Measures for Assessing Food Preferences in Abnormal Eating. Journal fur Verbraucherschutz und Lebensmittelsicherheit, 1(3), 180-186.

Sanftner, J. L., \& Crowther, J. H. (1998). Variability in self-esteem, moods, shame, and guilt in women who binge. The International journal of eating disorders, 23(4), 390-7. 
Sapolsky, R. M., Romero, L. M., Munck, A. U., (2000). How do glucocorticosteroids influence stress responses? Integrating permissive, suppressive, stimulatory and preparative actions. Endocrine Reviews 21, 55-89.

Schmidt-Reinwald, A., Pruessner, J. C., Hellhammer, D. H., Federenko I., Rohleder N., Schurmeyer, T.H., Kirschbaum, C. (1999). The cortisol response to awakening in relation to different challenge tests and a 12-hour cortisol rhythm. Life Sciences, $64,1653-1660$.

Schwarze, N. J., Oliver, J. M., \& Handal, P. J. (2003). Binge eating as related to negative self-awareness, depression, and avoidance of coping in undergraduates. Journal of College Student Development, 44, 644-652.

Schweiger U., Laessle R., Kittl S., Dickhaut B., Schweiger M., Pirke K. M. (1986). Macronutrient intake, plasma large neutral amino acids and mood during weightreducing diets. Journal of Neural Transmission, 67, 77-86.

Smyth, J.M., Ockenfels, M.C., Gorin, A.A., Catley, D., Porter, L.S., Kirschbaum, C., Hellhammer, D.H., \& Stone, A.A. (1997). Individual Differences in the Diurnal Cycle of Cortisol. Psychoneuroendocrinology, 22, 89-105.

Spielberger, C. D. (1983). State-Trait Anxiety Inventory for Adults. Palo Alto: Mind Garden.

Spoor, S. T. P., Bekker, M. H. J., Van Strien, T., \& van Heck, G. L. (2007) Relations between negative affect, coping, and emotional eating. Appetite, 48(3), 368-376.

Spring, B., Schneider, K., Smith, M., Kendzor, D., Appelhans, B., Hedeker, D., \& Pagoto, S. (2008). Abuse potential of carbohydrates for overweight carbohydrate cravers. Psychopharmacology 197(4), 637-647.

Stunkard A. J., Messick S. (1985). The three-factor eating questionnaire to measure dietary restraint, disinhibition and hunger. Journal Psychosomatic Research, 29, 71-83.

Suarez-Morales L., \& Lopez, B. (2009). The Impact of Acculturative Stress and Daily Hassles on Pre-adolescent Psychological Adjustment: Examining Anxiety Symptoms. The Journal of Primary Prevention, 30(3-4), 335-349.

Tamashiro, K. L. K., Nguyen, M. M. N., Fukikawa, T., Xu, T., Yun Ma, L., Woods, S. C., \& Sakai, R. R. (2004). Metabolic and endocrine consequences of social stress in a visible burrow system. Physiology and Behavior, 80, 683- 693.

Thomsen, D. K. (2006). The association between rumination and negative affect: A review. Cognition and Emotion, 20, 1216-1235. 
Torres, S. J, Nowson, C. A. (2007). Relationship between stress, eating behavior, and obesity. Nutrition, 23(11-12), 887-94.

Treynor, W., Gonzalez, R., Nolen-Hoeksema, S. (2003). Rumination Reconsidered: A Psychometric Analysis. Cognitive Therapy and Research, 27(3), 247-259.

Van Strien, T., \& Ouwens, M. A. (2003). Counterregulation in female obese emotional eaters: Schachter, Goldman, and Gordon's (1968) test of psychosomatic theory revisited. Eating Behaviors. 3, 329-340.

Van Strien, T., \& Ouwens, M. A. (2007). Effects of distress, alexithymia and impulsivity on eating. Eating Behaviors, 8, 251-257.

Van Strien, T., \& van de Laar, F. A. (2008). Intake of energy is best predicted by overeating tendency and consumption of fat is best predicted by dietary restraint: a 4-year follow-up of patients with newly diagnosed Type 2 diabetes. Appetite, $50,544-547$.

Van Strien, T., (2000). Ice-cream consumption, tendency toward overeating, and personality. International Journal of Eating Disorders 28, 460-464.

Van Strien, T., Cleven, A., \& Schippers, G. (2000). Restraint, tendency toward overeating and ice cream consumption. International Journal of Eating Disorders, 28, 333-338.

Van Strien, T., Frijters, J., Bergers, G., Defares, P. (1986). The Dutch Eating Behaviour Questionnaire for assessment of restrained, emotional and external eating behaviour. International Journal of Eating Disorders, 5, 295-315.

Van Strien, T., Schippers, G. M., Cox, W. M. (1995). On the relationship between emotional and external eating behavior. Addictive Behavior, 20(5), 585-594.

Verheul, Van den Brink, \& Geerlings (1999). A three-pathway psychobiological model of craving for alcohol. Alcohol and Alcoholism, 34, 197-222.

Wallis, D. J, \& Hetherington, M. M. (2009). Emotions and eating. Self-reported and experimentally induced changes in food intake under stress. Appetite. 52(2), 35562.

Wallis, D. J., \& Hetherington, M. M. (2004) Stress and eating: the effects of ego-threat and cognitive demand on food intake in restrained and emotional eaters. Appetite, $43,39-46$. 
Wang G. J., Volkow N. D., Logan J., Pappas N. R., Wong C. T., Zhu W., Netusil N., \& Fowler J. S. (2001). Brain dopamine and obesity. Lancet, 357, 354-2577.

Wardle, J., Steptoe, A., Oliver, G., Lipsey, Z. (2000). Stress, dietary restraint and food intake. Journal of Psychosomatic Research, 48, 195-202.

Watson, D., Clark L. A., \& Tellegen, A. (1988) Development and validation of brief measures of positive and negative affect: The PANAS scales. Journal of Personality and Social Psychology, 54(6), 1063-1070.

Weingarten, H. P., \& Elston, D. (1990) The phenomenology of food cravings. Appetite, 15, 231-246.

Wheatley, D. (1997). Stress, anxiety and depression. Stress Medicine, 13, 173- 177.

White, M. A., Whisenhunt, B. L., Williamson, D. A., Greenway, F. L., Netemeyer, R. G. (2002). Development and validation of the Food-Craving Inventory. Obesity Research, 10:107-114.

Williams, J. M. G., Mathews, A., MacLeod, C. (1996). The emotional Stroop task and psychopathology. Psychological Bulletin, 120(1), 3-24.

Wurtman, J. J. (1988) Carbohydrate cravings: a disorder of food intake and mood. Clinical Neuropharmacology, 11(suppl 1), S139-S145.

Wurtman, R. J., \& Wurtman, J. J. (1988). Do carbohydrates affect food intake via neurotransmitter activity? Appetite, 11 (suppl 1), 42-47.

Wurtman, R.J., \& Wurtman, J.J (1995). Brain serotonin, carbohydrate-craving, obesity and depression. Obesity Research, 3, 477S-490S.

Yeomans, M. R., Leitch, M., \& Mobini, S. (2008). Impulsivity is associated with the disinhibition but not restraint factor from the Three Factor Eating Questionnaire. Appetite, 50, 469-476.

York D. A. (1992) Central regulation of appetite and autonomic activity by CRH, glucocorticoids and stress. Progress in Neuroendocrinimmunology, 5, 153-165.

Zunszain P.A., Anacker C., Cattaneo A., Carvalho L. A., Pariante C. M. Glucocorticoids, cytokines and brain abnormalities in depression. (2010). Prog Neuropsychopharmacol Biol Psychiatry. [Epub ahead of print] 


\title{
Appendix A Study 2
}

\author{
Introduction
}

\section{Rumination}

Ruminative thinking has been described as passive, uncontrollable and perseverative thinking about negative mood and past or present events, and is a key feature of depression (Nolen-Hoeksema, 1991; Thomsen, 2006). Individuals who have the tendency to ruminate experience longer periods of distress (Nolen-Hoeksema, \& Morrow, 1991; Nolen-Hoesksema, Morrow, \& Fredrickson, 1993), and are more likely to engage in destructive behaviours such as alcohol abuse (Hull, Jouriles, \& Young, 1986; Nolen-Hoeksema, \& Morrow, 1991) and binge eating (Polivy and Herman, 1993). Kubiak et al. (2008) found that in a group of obese adolescents, negative affect and rumination strongly predicted increased desire to eat when confronted with the stress of daily hassles. Individuals, who ruminate when depressed, anxious, or faced with stressors, pay an excessive amount of attention to negative mood or problems in a passive way, without attempting help themselves (Nolen-Hoeksema, 1998). Rumination, therefore is a maladaptive coping strategy in itself, and seems to perpetuate the use of avoidant behaviours (such as emotional eating) in an attempt to suppress persistent negative thoughts or feelings, as suggested by the escape theory (Heatherton \& Baumeister, 1991; Kubiak, Vögele, Siering, Schiel, \& Weber, 2008; Nolen-Hoeksema, 1998).

In the present study, it was hypothesized that depressive symptomatology would be related to emotional eating, and this relationship would be partially mediated by rumination. 


\section{Implicit Measure of Food Preferences}

The majority of studies investigating food cravings and preferences have used direct measures, such as observations in the laboratory and self-report by subjects. Direct measures requiring self-report may be biased and can be affected by socially desirable responding. Study 2 therefore included an implicit measure of attitudes towards food at a more automatic level of cognitive processing, in order to avoid the potential problems associated with self-report.

There have been studies that used indirect measures such as the Implicit Associations Test or the Affective Priming Paradigm in order to assess implicit attitudes towards food (Roefs, Werrij, Smulders, \& Jansen, 2006). These implicit measures do not directly ask a participant for their food preferences, but instead, rely on reaction time tasks to measure attitudes in a relatively automatic way (de Houwer, Teige-Mocigemba, Spruyt, \& Moors, 2009; Fazio \& Olson, 2003). Several studies using implicit measures to assess differences in attitudes towards food have shown inconsistent results, with many studies revealing no differences between groups. However, there have been some studies revealing differences in implicit attitudes regarding food palatability in restrained eaters when compared to unrestrained eaters (Papies, Stroebe, \& Aarts, 2009), between anorexia nervosa patients and lean unrestrained eaters (Roefs et al., 2005), in obese versus overweight and healthy weight adults (Czyzewska \& Graham, 2008), and between obese and normal-weight children (Craeynest et al., 2005).

The present study used the Affective Priming Paradigm to assess implicit beliefs regarding the affective valence (positive or negative) of different types of food in a group 
of emotional eaters, as compared to non-emotional eaters. Differences in underlying automatic attitudes towards types of foods in emotional eaters might be related to their selectivity in eating specific foods (high in sugar, fat and carbohydrates) in times of distress. Therefore, implicit responses towards pictures of food was evaluated using the Affective Priming Paradigm, in the context of a moderate social stressor, in order to investigate the effects of both tendency towards emotional eating and the stressor on implicit attitudes towards different types of foods.

The implicit attitudes measure was developed using E-prime 2.0 software (Psychology software tools, inc., Pittsburgh, PA, 2009), and consisted of a total of 64 trials of picture-word pairings. Each picture (food or non-food) was followed once by a positive word, and once by a negative word. Presentation of food and non-food pictures were interspersed and selected randomly without replacement for each participant. Each picture was presented for $250 \mathrm{~ms}$, followed by a blank screen for $50 \mathrm{~ms}$, resulting in a stimulus-onset synchrony of $300 \mathrm{~ms}$ (Hermans, De Houwer, \& Eelen, 1994). The positive or negative word was then presented until the participant responded by pressing a premarked + or - key to indicate whether the word was positive or negative. There was an inter-trial interval of $1500 \mathrm{~ms}$.

The pictures included food pictures, as well as non-food pictures. The food pictures included four sweet items (e.g., chocolate), four carbohydrate items (e.g., pasta), four fast-food items (e.g., hamburger), and four healthy items (e.g., salad). The foodunrelated pictures included five positive items, five negative items, and five neutral items. The food unrelated pictures were chosen from the International Affective Picture System (Lang, Bradley, \& Cuthbert, 2008) based on their affective and arousal ratings 
(scale from 1-9). The mean ratings for negative pictures were affective $M=2.68$, arousal $M=5.44$; for positive pictures affective $M=7.90$, arousal $M=4.16$; and for neutral pictures affective $\mathrm{M}=5.06$, arousal $\mathrm{M}=2.73$.

Thirty-two positive words (e.g., love) and thirty-two negative words (e.g., dreadful) were used as the target words that the participants were instructed to classify using a key press. These words were previously used by Roefs et al. (2005) as target words in an affective priming task, and are based on norms developed by Bellezza, Greenwald, and Banaji (1986).

The prime (picture) should affect the participants' response time to the target word; that is, response time should be faster when the picture and word are congruent (both positive, or both negative) than when they are incongruent. Implicit attitudes are measured by comparing reaction times when a picture is paired with a positive word versus when the same picture is paired with a negative word (if the attitude towards a food is positive, response times should be faster when it is paired with a positive word, then when paired with a negative word.)

In the present study it was hypothesized that based on the implicit attitudes measure (Affective Priming Paradigm), attitudes would be more positive for foods high in sugar and carbohydrates, than other types of foods, and that attitudes would be moderated by emotional eating status and stressor condition. Specifically, emotional eating would be related to stronger positive attitudes towards foods high in sugar and carbohydrates and this effect would be even more pronounced in the stressor condition than in the control condition. 


\section{Participants}

Undergraduate female students, aged 18-32 years $(n=90, M$ age $=20.25$ years $S D=3.32$ ) served as participants for a study on student performance under conditions of distraction. Participants were told that they would be asked to fill out a questionnaire booklet, to perform a 10-minute task, as well as another 5-minute task on the computer. Participants received $1.5 \%$ course credit towards an Introductory Psychology course as compensation for participating in the study.

\section{Procedure}

The study was conducted during the 2010 winter semester of the academic school year (January - March 2010). Participants were instructed prior to the study that they must not eat (including chewing gum), drink (including water), or smoke for at least 1 hour before the experimental session, and this was verified upon arrival. Participants were randomly assigned to a Stressor or Control condition, and were tested individually after the study was described and an informed consent form was read and signed. Participants completed background information and medical information questionnaires, and went on to complete questionnaires assessing depressive symptoms (extended Beck Depression Inventory with additional items for atypical depression, BDI; Beck, Ward, Mendelson, Mock, \& Erbaugh, 1961), rumination (Ruminative Responses Scale, RRS; Nolen-Hoeksema \& Morrow, 1991), and eating habits (Dutch Eating Behavior Questionnaire, DEBQ; Van Strien, Frijters, Bergers \& Defares, 1986).

As in Experiment 1, participants in the stressor condition were then asked to prepare a speech about their employment potential that they would be giving in front of a 6-person panel consisting of 3 professors and 3 graduate students, followed by a brief 
mental-math task (Trier Social Stress Test; Kirschbaum, Pirke \& Hellhammer, 1993). They were told that they have the next 10 minutes to prepare this speech, and that they would be evaluated on their presentation. Subjects in the control condition were given a task to complete comprising word and number games. They also had 10 minutes to complete the task.

At the end of the 10 minute task, participants in the stressor condition were told that there were not enough students and professors to complete the panel at the current time, and that they would no longer be performing the speech. Those in the control condition were asked to stop filling out the word and number games if they had not already finished. All subjects were asked to complete questionnaires that included initial mood ratings (Positive and Negative Affect Schedule with additional adjectives, PANAS; Watson, Clark \& Tellegan, 1988, state anxiety; State Anxiety Inventory, STAI; Speilberger, 1983) and a stress appraisal measure (Stress Appraisal Measure, SAM; Peacock and Wong, 1986).

Participants were then asked to complete a second computer-based task for approximately 5-min, which was designed to see how people react to different stimuli. They were briefly presented with a series of pictures on the computer screen, each followed by a word. The instructions were to classify each word as being either positive or negative by pressing one of two keys labeled with + or - . The participant was not to respond to the picture; they were only to respond to the word. The computer task took approximately five minutes. There was a practice that consisted of ten trials using neutral pictures, each followed by a positive or negative word. 
After finishing the computer task, participants were asked to complete questionnaires measuring general food cravings (General Food Cravings Questionnaire State; Nijs, Franken \& Muris, 2006), and specific food cravings (Food Craving Inventory with additional food options, FCI; White, Whisenhunt, Williamson, Greenway \& Netemeyer, 2002)

Participants were debriefed and given a Consent form for use of data, once the nature of the deception used in the study had been explained. Participants were given a Contact Information sheet and were compensated with course credit. Measures

The following questionnaires were used: Beck Depression Inventory (BDI; Beck, Ward, Mendelson, Mock, \& Erbaugh, 1961) with additional items for atypical depression, Ruminative Response Scale (Treynor, Gonzalez \& Nolen-Hoeksema, 2003), Positive and Negative Affect Schedule with additional adjectives, (PANAS; Watson, Clark \& Tellegan, 1988), State-Trait Anxiety Inventory (Speilberger, 1983), Stress Appraisal Measure (SAM; Peacock and Wong, 1986), General Food Cravings Questionnaire, State (GFCQ; Nijs, Franken \& Muris, 2006), Food-Craving Inventory (FCI; White, Whisenhunt, Williamson, Greenway \& Netemeyer, 2002), and The Dutch Eating Behavior Questionnaire (Van Strien, Frijters, Bergers \& Defares, 1986).

Rumination. The Ruminative Response Scale (Nolen-Hoeksema \& Morrow, 1991) is a 22-item scale that was used to measure the general tendency to ruminate when faced with problems. Responses are scored from 1 "Almost Never" to 4 "Almost Always". Nolen-Hoeksema \& Morrow reported good internal reliability with a Cronbach alpha of .89. The scale is composed of three factors: (1) Reflection, and (2) Brooding, and 
(3) Depression-related items. Treynor et al. (2003) found that after removal of depression-related items, Reflection and Brooding items accounted for $50.5 \%$ of the variance, with coefficient alphas of .72 and .77 , respectively.

Results

Depressive symptomatology, rumination, and emotional eating. It was hypothesized that the tendency to engage in rumination would mediate the relationship between depressive symptomatology and emotional eating behaviours. It was also expected that differences may be seen between individuals endorsing a high level of typical depressive symptoms, versus those endorsing symptoms of atypical depression. As seen in Table 1, both typical and atypical depressive symptomatology were related to emotional eating behaviours, with both depression-related rumination and brooding as potential mediators. As illustrated in Figure 1, when depression-related rumination was included as a mediator, typical depressive symptomatology was no longer a significant predictor of emotional eating behaviour. The $95 \%$ confidence intervals indicated that the mediated path was significant (CI: .002, .068), suggesting that the tendency to engage in depression-related rumination fully mediated the relationship between typical depressive symptomatology and emotional eating behaviours. Brooding was not found to be a significant mediator of the relationship between typical depressive symptoms and emotional eating behaviours. Both forms of rumination (depression-related and brooding) were not found to be significant mediators of the relationship between atypical depression and emotional eating behaviours. 
Table 1.

Pearson Correlations among Depressive Symptomatology, Rumination, and Emotional

Eating Behaviours

\begin{tabular}{|c|c|c|c|c|c|c|c|}
\hline Variable & 1 & 2 & 3 & 4 & 5 & 6 & 7 \\
\hline \multicolumn{8}{|l|}{ Depressive Symptoms } \\
\hline 1. Typical & --- & $.468^{* * *}$ & $.651^{* * *}$ & $.691^{* * *}$ & $.602^{* * *}$ & .208 & $.226^{* *}$ \\
\hline 2. Atypical & $.468^{* * *}$ & --- & $.268^{*}$ & $.299^{* *}$ & $.309^{* *}$ & .013 & $.350^{* *}$ \\
\hline 3. Rumination & $.651^{* * *}$ & $.268^{*}$ & --- & $.901^{* * *}$ & $.823^{* * *}$ & $.680^{* * *}$ & $.288^{* *}$ \\
\hline 4. Depression-related & $.691^{* * *}$ & $.299^{* *}$ & $.901^{* * *}$ & --- & $.656^{* * *}$ & $.354^{* *}$ & $.317^{* *}$ \\
\hline 5. Brooding & $.602^{* * *}$ & $.309^{* *}$ & $.823^{* * *}$ & $.656^{* * *}$ & --- & $.452^{* * *}$ & $.219^{*}$ \\
\hline 6. Reflection & .208 & .013 & $.680^{* * *}$ & $.354^{* *}$ & $.452^{* * *}$ & --- & .111 \\
\hline 7. Emotional Eating Behaviours & $.226^{*}$ & $.350^{* *}$ & $.288^{* *}$ & $.317^{* *}$ & $.219^{*}$ & .111 & --- \\
\hline
\end{tabular}

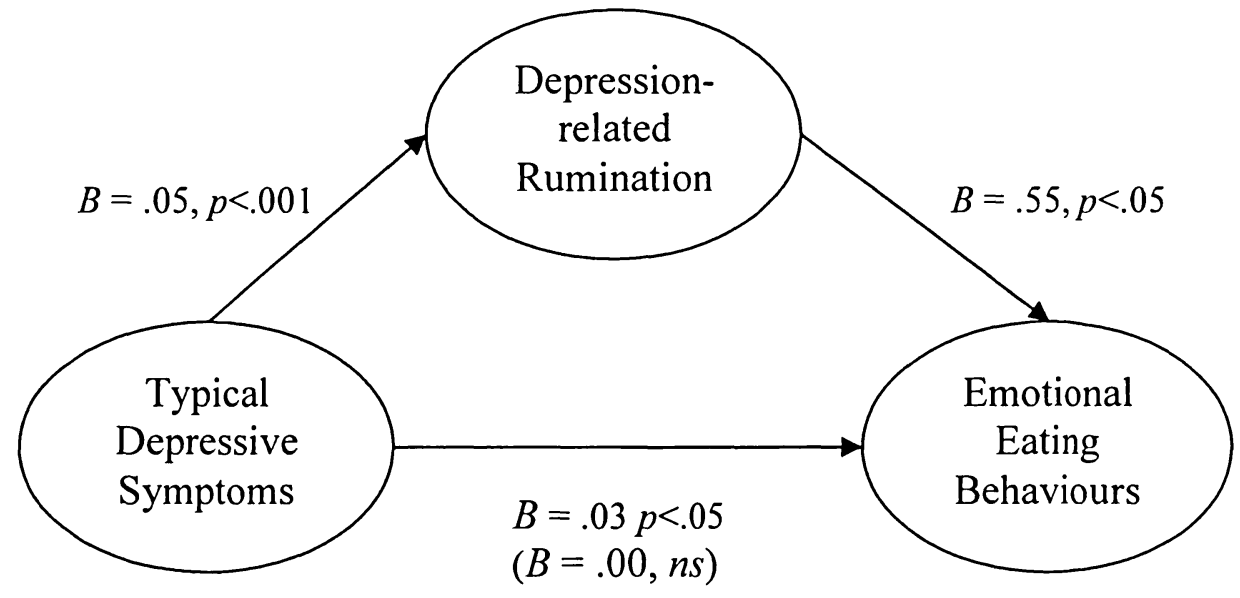

Figure 1. Depression-related Rumination as a Mediator between Typical Depressive Symptomatology and Emotional Eating Behaviours. 
Implicit Measure of Food Preferences. $\mathrm{t}$ was hypothesized that emotional eating would be related to stronger positive attitudes towards foods high in sugar and carbohydrates and this effect would be even more pronounced in the stressor condition than in the control condition.

In order to measure attitudes towards each type of food, positivity indices were calculated for each food picture. The positivity index was calculated by subtracting the reaction time when a specific picture was paired with a positive word, from the reaction time when the same picture was paired with a negative word (Positivity Index = RT negative target word - RT positive target word). Positivity indices for each picture of food were grouped together by calculating the mean positivity indices for sweet foods, carbohydrate foods, fast foods, and healthy foods. Positivity indices for each food type were used as the dependent variables in subsequent analyses. Response times on trials with errors were excluded from analyses.

A Regression Analysis was conducted to assess whether there was a general preference for a specific type of food. However, food type was not significantly related to positivity indices $(F=.056, p=.81)$.

Hierarchical Regression Analyses were conducted to assess emotional eating and condition (stressor or control), as well as the interaction between them, as predictors of positivity indices for each food type. Results were non-significant for all food types: sweet $(F=.32, p=.81)$, carbohydrate $(F=.46, p=.71)$, fat $(F=1.19, p=.32)$, and healthy $(F=.29, p=.84)$. 


\section{Appendix B \\ Informed Consent (Study 1)}

The purpose of an informed consent is to ensure that you understand the purpose of the study and the nature of your involvement. The informed consent has to provide sufficient information such that you have the opportunity to determine whether you wish to participate in the study.

Study title: Student responses to challenging situations

Study personnel: $\quad$ Vasilinka Tsar (Researcher, 613-520-2600 ext. 4199)

Ashley Charbonneau (Researcher, 613-520-2600 ext. 4199)

Kate Raspopow (Researcher, 613-520-2600 ext. 4199)

Dr. Hymie Anisman (Faculty Investigator, 613-520-2600 ext. 2699)

Dr. Alfonso Abizaid (Faculty Investigator, 613-520-2600 ext. 1544)

If you have any ethical concerns about how this study was run please contact: Dr. Avi Parush, Chair of Carleton University Ethics Committee for Psychological Research, 613-520-2600 ext. 6026 or Dr. Janet Mantler, Chair of Dept. of Psychology, 613-520-2600 ext. 4173

Purpose and Task Requirements: Students experience a wide variety of events in their daily lives, ranging from the mundane, to the challenging. However, perceptions of what is challenging or stressful may vary between people as well as between situations. Also, individuals may cope with challenges differently, depending on the situation at hand. Furthermore, daily patterns, such as eating may change in response to stressors and these events may even influence food preferences. Various stages of the menstrual cycle may also influence how individuals respond to situations, as well as eating and cravings patterns. In this study we are interested in individual responses to a brief task (similar to one that may occur in daily student life). You will be asked to complete a series of questionnaires that will include some personal information about yourself, to perform a brief task, and to complete several remaining questionnaires. As we are also interested in physiological reactions to stress, we ask your consent to take four saliva samples. The sample is simply taken by placing a piece of dental cotton in your mouth for two minutes. The saliva samples will be analyzed for levels of cortisol and alpha-amylase (stress related hormones) as well as estrogen and progesterone (reproductive hormones). For participating in this session you will receive $1.5 \%$ of experimental credit. At the end of this session you will be debriefed about this study in its entirety, and what the researchers are expecting to find.

Potential Risk and Discomfort: There may be some emotional discomfort when performing the assigned task and thinking about the emotions you experience in response to various challenging situations.

Anonymity/Confidentiality: The data collected in this study will be kept confidential. Your informed consent form will be separated from your questionnaire and kept in a separate and secured file by one of the research investigators who will keep this information confidential. It will be associated with a code, and only this code will identify your questionnaire. We will need to have a code associated with your questionnaire and saliva samples so that we are able to match up your responses at the end of the study. The data will also be stored in a secured data file that is only accessible by the researcher and research assistants. *It should be noted that based on preliminary analyses, it may be necessary to contact participants in order to ensure participant personal well-being.

Right to Withdraw: Your participation in this study is entirely voluntary. At any point during the study you have the right to not complete certain questions or to withdraw entirely without penalty. I have read the above description of the study concerning the daily experiences of students. The data collected will be used in research publications and/or for teaching purposes. My signature indicates that I agree to participate in the study, and this in no way constitutes a waiver of my rights.

Full Name (please print):

Participant Signature: Date: 


\section{Informed Consent (Study 2)}

The purpose of an informed consent is to ensure that you understand the purpose of the study and the nature of your involvement. The informed consent has to provide sufficient information such that you have the opportunity to determine whether you wish to participate in the study.

Study title: Student responses to challenging situations Study personnel: $\quad$ Ashley Charbonneau (Researcher, 613-520-2600 ext. 4199)

Dr. Hymie Anisman (Faculty Investigator, 613-520-2600 ext. 2699)

Dr. Kim Matheson (Faculty Investigator, 613-520-2600 ext. 2684)

If you have any ethical concerns about how this study was run please contact: Dr. Monique Sénéchal, Chair of Carleton University Ethics Committee for Psychological Research, 613-520-2600 ext. 1155 or Dr. Janet Mantler, Chair of Dept. of Psychology, 613-520-2600 ext. 4173

Purpose and Task Requirements: Students experience a wide variety of events in their daily lives, ranging from the mundane, to the challenging. Student performance may vary between people as well as between situations. The ability to perform under conditions of distraction can affect how well individuals succeed at different tasks. Also, individuals may cope with challenges differently, depending on the situation at hand. Furthermore, daily patterns, such as eating and sleeping may affect daily school performance. In this study we are interested in individual responses to two brief tasks (similar to ones that may occur in daily student life) that will tell us how you deal with life challenges. You will be asked to fill out a few questionnaires about yourself including background information, medical information, your daily experiences, and how you deal with them. We will then ask you to do a 10 -minute task. Then we'll have a few more questionnaires for you to complete. Then we will ask you to do another short task and have you complete a few more questionnaires.

For participating in this session you will receive $1.5 \%$ of experimental credit. At the end of this session you will be debriefed about this study in its entirety, and what the researchers are expecting to find.

Potential Risk and Discomfort: There may be some emotional discomfort when performing the assigned task and thinking about the emotions you experience in response to various challenging situations.

Anonymity/Confidentiality: The data collected in this study will be kept confidential. Your informed consent form will be separated from your questionnaire and kept in a separate and secured file by one of the research investigators who will keep this information confidential. It will be associated with a code, and only this code will identify your questionnaire. We will need to have a code associated with your questionnaire so that we are able to match up your responses at the end of the study. The data will also be stored in a secured data file that is only accessible by the researcher and research assistants.

Right to Withdraw: Your participation in this study is entirely voluntary. At any point during the study you have the right to not complete certain questions or to withdraw entirely without penalty.

I have read the above description of the study concerning the daily experiences of students. The data collected will be used in research publications and/or for teaching purposes. My signature indicates that I agree to participate in the study, and this in no way constitutes a waiver of my rights.

Full Name (please print):

Participant Signature: Date: 


\section{Informed Consent to the Use of Data (Study 2)}

The purpose of an informed consent is to ensure that you now understand the true purpose of the study and that you agree to allow your data to be used for research and teaching purposes. Because you were only told of the procedures and not the purpose of this study at the outset, we are now asking for your consent to allow your data to be used for research and teaching purposes.

Purpose. The purpose of this study is to assess the effect of stress on eating, food craving and automatic attitudes towards different types of food.

Anonymity/Confidentiality. The data collected in this study are kept anonymous and confidential. The consent forms are kept separate from your responses.

Right to withdraw data. You have the right to indicate that you do not wish your data to be used in this study. If you indicate this is your choice, then all measures you have provided will be destroyed.

Signatures: I have read the above description of the study investigating stress and eating. The data in the study will be used in research publications or for teaching purposes. My signature indicates that I agree to allow the data I have provided to be used for these purposes.

Full Name (Print):

Participant Signature:

Date:

Researcher Signature:

Date: 


\section{Appendix C}

\section{Background and Medical Information}

Age:

Year of study: $1^{\text {st }}$ year

$2^{\text {nd }}$ year

$3^{\text {rd }}$ year $4^{\text {th }}$ year

What is your citizenship status?

Canadian citizen Landed immigrant Student visa

What is your first language?

If your first language is not English, how long have you been fluent in reading, writing and comprehension of the English language?

What is your ethnic/racial background?

What is your religion, if any?

What is your current relationship status (please check ONE that best applies to you)?

Single, and not seeing anyone

Am going out with someone

Am living with or married to an intimate other

Have recently broken up

Is your current (or most recent) partner: Male

OR Female $?$

If you are currently in a relationship:

How long have you been in this relationship?

Is this relationship a source of support to you? No

Yes

Current height:

Current weight:

Are you currently on a diet to lose weight?

No

Yes

If yes, which type(s)?

General calorie reduction

Glycemic Index

High Protein

Low Carb

South Beach 
Pharmaceuticals, weight loss pills, herbal remedies (e.g., Proactol, Hydroxycut, Phentermine). If so, please specify

Other:

If yes, for how long have you been dieting?

Approximately how much weight have you lost in this time?

Have you been on a diet to lose weight in the past year? No

Yes

If yes, how long ago?

For how long were you dieting?

How much weight did you lose?

Do you currently smoke? No ___ Yes

If yes, on average, how many cigarettes/day?

Are you suffering from a medical illness (e.g., type 2 diabetes, hyperthyroidism, etc.)?

No

If yes, please specify:

Are you on any of the following medications (please check all that apply)?

Anti-inflammatories (please specify)

Anti-depressants (please specify)

Anti-anxieties (please specify)

Allergy medication (please specify)

Birth control (please specify)

Other prescription drugs (please specify)

Have you taken any of these medications in the past 24 hours?

No

Yes

\section{If yes:}

Which medications?

What time did you take it/them?

How much did you take?

What time did you wake up this morning?

When was the last time you ate today?

What did you eat? 
How hungry are you right now?

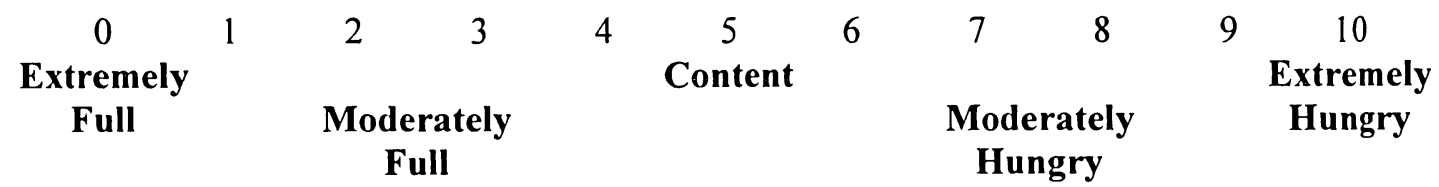




\section{Appendix D \\ Beck Depression Inventory BDI- 24 item scale}

On this questionnaire are groups of statements. Please read the entire group of statements in each category. Then pick out $\mathrm{ONE}$ statement in that group which best describes the way you feel. Check off the number beside the statement you have chosen.

1. 0 _ 0 I do not feel sad

$1=$ I feel sad or blue

$2 \mathrm{a}=\mathrm{I}$ am blue or sad all of the time and I can't snap out of it

$2 b=I$ am so sad or unhappy that it is very painful

3 = I am so sad or unhappy that I can't stand it

2. __ $0=$ I am not particularly pessimistic or discouraged about the future

$1=\mathrm{I}$ feel discouraged about the future

$2 \mathrm{a}=\mathrm{I}$ feel I have nothing to look forward to

$2 \mathrm{~b}=$ I feel I won't every get over my troubles

$3=$ I feel that the future is hopeless and things cannot improve

3. $0=\mathrm{I}$ do not feel like a failure

$1=$ I feel I have failed more than the average person

$2 \mathrm{a}=\mathrm{I}$ feel I have accomplished very little that is worthwhile or that means anything

$2 \mathrm{~b}=$ As I look back on my life, all I can see is a lot of failures

$3=$ I feel I am a complete failure as a person

4. _ $0=\mathrm{I}$ am not particularly dissatisfied

$1 \mathrm{a}=\mathrm{I}$ feel bored most of the time

$1 b=I$ don't enjoy things the way I used to

2 = I don't get satisfaction out of anything anymore

$3=$ I am dissatisfied with everything

5. _ 0 _ 0 I don't feel particularly guilty

1 _ 1 I feel bad or unworthy a good part of the time

$2 \mathrm{a}=\mathrm{I}$ feel quite guilty

$2 b=$ I feel bad or unworthy practically of the time now

$3=$ I feel as though I am very bad or worthless

6. $\quad 0$ _ $\quad$ I I don't feel I am being punished

_ 1 = I have a feeling that something bad may happen to me

$2=$ I feel I am being punished or will be punished

$3 a=I$ feel I deserve to be punished

$3 b=$ I want to be punished 
7. _ $0=$ I don't feel disappointed in myself

$1 \mathrm{a}=\mathrm{I}$ am disappointed in myself

$\mathrm{lb}=\mathrm{I}$ don't like myself

$2=\mathrm{I}$ am disgusted with myself

3 = I hate myself

8. $0=$ I do not feel I am any worse than anybody else

$1=$ I am very critical of myself for my weaknesses or mistakes

$2 \mathrm{a}=$ I blame myself for everything that goes wrong

$2 b=$ I feel I have many bad faults

9. 0 _ 0 I don't have thoughts of harming myself

1 = I have thoughts of harming myself but I would not carry them out

$2 \mathrm{a}=$ I feel I would be better off dead

$2 \mathrm{~b}=\mathrm{I}$ have definite plans about committing suicide

$2 \mathrm{c}=$ I feel my family would be better off if I were dead

3 = I would kill myself if I could

10. $0=$ I don't cry anymore than usual

$1=$ I cry more now than I used to

$2=$ I cry all the time now. I can't stop it

$3=$ I used to be able to cry but now I can't cry at all even though I want to

11. _ $0=$ I am no more irritated now than I ever am

$1=I$ get annoyed or irritated more easily than I used to

$2=I$ get irritated all the time

$3=$ I don't get irritated at all the things that used to irritate me.

12. _ $0=$ I have not lost interest in other people

$1=$ I am less interested in other people than I used to be

$2=$ I have lost most of my interest in other people and I have little feeling for them

3 = I have lost all my interest in other people and don't care about them at all

13. $0=$ I make decisions about as well as ever

$1=\mathrm{I}$ am less sure of myself now and try to put off making decisions

2 = I can't make decisions anymore without help

3 = I can't make decisions at all anymore

14. $0=\mathrm{I}$ don't feel I look any worse than I used to

1 = I am worried that I am looking old or unattractive

$2=$ I feel that there permanent changes in my appearance and they make me look unattractive

3 = I feel that I am ugly or repulsive looking 
15. $0=$ I can work about as well as before

la $=$ It takes extra effort to get started at doing something

$1 \mathrm{~b}=\mathrm{I}$ don't work as well as I used to

$2=$ I have to push myself very hard to do anything

3 = I can't do any work at all

16. $0=$ I can sleep as well as usual

$1=$ I wake up more tired in the morning than I used to

$2=$ I wake up 1-2 hours earlier than usual and find it hard to get back to sleep

3 = I wake up early every day and can't get more than 5 hours sleep

17. $0=$ I don't get anymore tired than usual

$1=$ I get tired more easily than I used to

$2=$ I get tired from doing anything

3 = I get too tired to do anything

18a. _ $0=$ My appetite is no worse than usual

$1=$ My appetite is not as good as it used to be

2 = My appetite is much worse now

$3=$ I have no appetite at all any more

18b. __ $0=$ I am not eating more than usual

$1=\mathrm{I}$ am eating a little more than usual

$2=$ I am eating somewhat more than usual

3 = I am eating a lot more than usual

18c. $0=$ I have had no change in food preferences lately

1 = I have been craving more carbohydrates (starches or sweets lately)

2 = I have had irresistible craving for sweets and starches lately

19a. _ $0=$ I haven't lost much weight, if any, lately

$1=$ I have lost more than 5 pounds

$2=$ I have lost more than 10 pounds

$3=$ I have lost more than 15 pounds

19b. _ $0=$ I have not gained any weight lately

$1=$ I have gained more than 5 pounds

$2=$ I have gained more than 10 pounds

$3=$ I have gained more than 15 pounds 
20. $0=$ I am no more concerned about my health than usual

$1=\mathrm{I}$ am concerned about aches and pains or upset stomach or constipation or other unpleasant feelings in my body

$2=$ I am so concerned with how I feel or what I feel that it's hard to think of much else

3 = I am completely absorbed in what I feel

21. $0=\mathrm{I}$ have not noticed any recent change in my interest in sex

$1=\mathrm{I}$ am less interested in sex than I used to be

$2=\mathrm{I}$ am much less interested in sex now

$3=$ I have lost interest in sex completely

22. $0=\mathrm{I}$ have not had any increase in nightly sleep length lately

$1=\mathrm{I}$ have had at least 1 -hour increase in sleep length

$2=\mathrm{I}$ have had at least 2-hour increase in sleep length

$3=$ I have had at least 3-hour increase in sleep length

My average nightly sleep length in the past week is:

hours

23. $0=\mathrm{I}$ am not feeling more fatigued than usual

1 = I feel more fatigue than usually lately, but it does not interfere with my daily

functioning

2 = I feel more fatigue than usually lately, and it interferes somewhat with my

daily functioning

3 = I feel more fatigue than usually lately and it significantly interferes with my daily functioning

24. $0=$ I have not had any mood swings or slumps lately

$1=$ I have had some mood swings or slumps lately but very minor

2 - I have had more mood swings or slumps than usual

3 = I have had sever mood swings or slumps lately 


\section{Appendix E \\ Positive and Negative Affect Schedule with additional adjectives}

Using the rating scale beside each item, please indicate how much each adjective describes how you feel at the moment. There are no right or wrong answers, we just want you to be as honest as possible in indicating how you're feeling right now.

\begin{tabular}{|c|c|c|c|c|c|c|c|c|c|}
\hline Active .................. & ... Not at all & 0 & 1 & 2 & 3 & 4 & 5 & 6 & Extremely \\
\hline Afraid....................... & .... Not at all & 0 & 1 & 2 & 3 & 4 & 5 & 6 & Extremely \\
\hline Alert................... & .... Not at all & 0 & 1 & 2 & 3 & 4 & 5 & 6 & Extremely \\
\hline 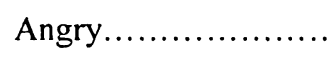 & $\ldots$ Not at all & 0 & 1 & 2 & 3 & 4 & 5 & 6 & Extremely \\
\hline Annoyed................. & ... Not at all & 0 & 1 & 2 & 3 & 4 & 5 & 6 & Extremely \\
\hline 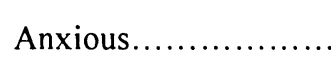 & $\ldots$ Not at all & 0 & 1 & 2 & 3 & 4 & 5 & 6 & Extremely \\
\hline Ashamed................. & .. Not at all & 0 & 1 & 2 & 3 & 4 & 5 & 6 & Extremely \\
\hline Attentive................. & $\ldots$ Not at all & 0 & 1 & 2 & 3 & 4 & 5 & 6 & Extremely \\
\hline Bored..................... & $\ldots$ Not at all & 0 & 1 & 2 & 3 & 4 & 5 & 6 & Extremely \\
\hline Confused................ & Not at all & 0 & 1 & 2 & 3 & 4 & 5 & 6 & Extremely \\
\hline Contempt................ & Not at all & 0 & 1 & 2 & 3 & 4 & 5 & 6 & Extremely \\
\hline Depressed................ & Not at all & 0 & 1 & 2 & 3 & 4 & 5 & 6 & Extremely \\
\hline Determined............... & Not at all & 0 & 1 & 2 & 3 & 4 & 5 & 6 & Extremely \\
\hline Disdain...................... & .. Not at all & 0 & 1 & 2 & 3 & 4 & 5 & 6 & Extremely \\
\hline Disgust.................... & Not at all & 0 & 1 & 2 & 3 & 4 & 5 & 6 & Extremely \\
\hline Distressed................ & Not at all & 0 & 1 & 2 & 3 & 4 & 5 & 6 & Extremely \\
\hline Embarrassed............. & Not at all & 0 & 1 & 2 & 3 & 4 & 5 & 6 & Extremely \\
\hline Enraged................... & Not at all & 0 & 1 & 2 & 3 & 4 & 5 & 6 & Extremely \\
\hline Enthusiastic............... & .Not at all & 0 & 1 & 2 & 3 & 4 & 5 & 6 & Extremely \\
\hline Excited.................... & .. Not at all & 0 & 1 & 2 & 3 & 4 & 5 & 6 & Extremely \\
\hline Frustrated................ & Not at all & 0 & 1 & 2 & 3 & 4 & 5 & 6 & Extremely \\
\hline Guilty.................... & $\ldots$ Not at all & 0 & 1 & 2 & 3 & 4 & 5 & 6 & Extremely \\
\hline Happy................... & .. Not at all & 0 & 1 & 2 & 3 & 4 & 5 & 6 & Extremely \\
\hline Helpless.................. & Not at all & 0 & 1 & 2 & 3 & 4 & 5 & 6 & Extremely \\
\hline Hostile..................... & . Not at all & 0 & 1 & 2 & 3 & 4 & 5 & 6 & Extremely \\
\hline Humiliated............... & Not at all & 0 & 1 & 2 & 3 & 4 & 5 & 6 & Extremely \\
\hline
\end{tabular}




\begin{tabular}{|c|c|c|c|c|c|c|c|c|c|}
\hline Indifferent.............. & . Not at all & 0 & 1 & 2 & 3 & 4 & 5 & 6 & Extremely \\
\hline Infuriated................ & Not at all & 0 & 1 & 2 & 3 & 4 & 5 & 6 & Extremely \\
\hline 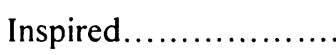 & . Not at all & 0 & 1 & 2 & 3 & 4 & 5 & 6 & Extremely \\
\hline Interested............... & Not at all & 0 & 1 & 2 & 3 & 4 & 5 & 6 & Extremely \\
\hline 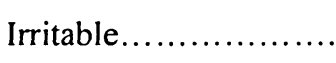 & Not at all & 0 & 1 & 2 & 3 & 4 & 5 & 6 & Extremely \\
\hline Jittery ................... & Not at all & 0 & 1 & 2 & 3 & 4 & 5 & 6 & Extremely \\
\hline Nervous.................. & Not at all & 0 & 1 & 2 & 3 & 4 & 5 & 6 & Extremely \\
\hline Proud................... & Not at all & 0 & 1 & 2 & 3 & 4 & 5 & 6 & Extremely \\
\hline Regretful................ & Not at all & 0 & 1 & 2 & 3 & 4 & 5 & 6 & Extremely \\
\hline Responsible............. & Not at all & 0 & 1 & 2 & 3 & 4 & 5 & 6 & Extremely \\
\hline Sad.......................... & Not at all & 0 & 1 & 2 & 3 & 4 & 5 & 6 & Extremely \\
\hline Scared.................. & Not at all & 0 & 1 & 2 & 3 & 4 & 5 & 6 & Extremely \\
\hline Strong.................. & Not at all & 0 & 1 & 2 & 3 & 4 & 5 & 6 & Extremely \\
\hline Unhappy.................. & Not at all & 0 & 1 & 2 & 3 & 4 & 5 & 6 & Extremely \\
\hline Upset................... & Not at all & 0 & 1 & 2 & 3 & 4 & 5 & 6 & Extremely \\
\hline Worried... & Not at all & 0 & 1 & 2 & 3 & 4 & 5 & 6 & Extremely \\
\hline
\end{tabular}




\section{Appendix F \\ State-Trait Anxiety Inventory - STAI (State Anxiety)}

A number of statements which people have used to describe themselves are given below. Read each statement and then circle the correct response to indicate how you feel right now, that is, at this moment. There are no right or wrong answers. Do not spend too much time on any one statement but give the answer which seems to describe your present feelings best.

$\begin{array}{cccc}\begin{array}{c}\text { Not at } \\ \text { All }\end{array} & \text { Somewhat } & \begin{array}{c}\text { Moderately } \\ \text { So }\end{array} & \begin{array}{c}\text { Very } \\ \text { Much So }\end{array}\end{array}$

1. I feel calm

2. I feel secure

$\begin{array}{llll}1 & 2 & 3 & 4 \\ 1 & 2 & 3 & 4 \\ 1 & 2 & 3 & 4 \\ 1 & 2 & 3 & 4 \\ 1 & 2 & 3 & 4 \\ 1 & 2 & 3 & 4 \\ 1 & 2 & 3 & 4\end{array}$

7. I am presently worrying over possible misfortunes

8. I feel satisfied

9. I feel frightened

10. I feel comfortable

11. I feel self-confident

12. I feel nervous

1

13. I am jittery

14. I feel indecisive

15. I am relaxed

1

16. I feel content

17. I am worried

1

18. I feel confused

1

19. I feel steady

1

2

3

20. I feel pleasant

34

3




\section{Appendix G \\ The Stress Appraisal Measure (SAM)}

This questionnaire is concerned with your thoughts about various aspects of the task you just performed. There are no right or wrong answers. Please respond according to how you view this situation right now, that is, at this moment. Please answer ALL questions. Answer each question by CIRCLING the appropriate number corresponding to the following scale.

$\begin{array}{ccccc}1 & 2 & 3 & 4 & 5 \\ \text { Not at all } & \text { Slightly } & \text { Moderately } & \text { Considerably } & \text { Extremely }\end{array}$

1. Is this a totally hopeless situation?

$\begin{array}{lllll}1 & 2 & 3 & 4 & 5 \\ 1 & 2 & 3 & 4 & 5 \\ 1 & 2 & 3 & 4 & 5\end{array}$

3. Is the outcome of this situation uncontrollable by anyone?

4. Is there someone or some agency I can turn to for help if I need it?

5. Does this situation make me feel anxious?

6. Does this situation have important consequences for me?

7. Is this going to have a positive impact in me?

8. How eager am I to tackle this problem?

9. How much will I be affected by the outcome of this situation?

10. To what extent can I become a stronger person because of this problem?

11. Will the outcome of this situation be negative?

12. Do I have the ability to do well in this situation?

13. Does this situation have serious implications for me?

14. Do I have what it takes to do well in this situation?

15. Is there help available to me for dealing with this problem?

16. Does this situation tax or exceed my coping resources?

17. Are there sufficient resources available to help me in dealing?

18. Is this beyond anyone's power to do anything about this situation?

19. To what extent am I excited thinking about the outcome of this situation?

$\begin{array}{lllll}1 & 2 & 3 & 4 & 5\end{array}$

$\begin{array}{lllll}1 & 2 & 3 & 4 & 5 \\ 1 & 2 & 3 & 4 & 5\end{array}$

$\begin{array}{lllll}1 & 2 & 3 & 4 & 5 \\ 1 & 2 & 3 & 4 & 5 \\ 1 & 2 & 3 & 4 & 5\end{array}$




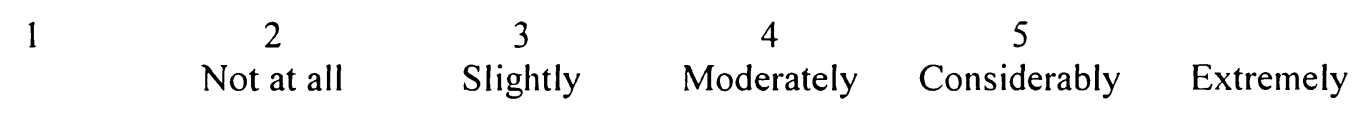

20. How threatening is this situation?

21 . Is the problem unresolvable by anyone?

22. Will I be able to overcome the problem?

23 . Is there anyone who can help me manage the problem?

24. To what extent do I perceive this situation as stressful?

25. Do I have the skills necessary to achieve a successful outcome to this situation?

26. To what extent does this event require coping efforts on $\quad \begin{array}{lllllll}1 & 2 & 3 & 4 & 5\end{array}$ my part?

27. Does this situation have long-term consequences for me?

28. Is this going to have a negative impact on me?

29. How anxious do I feel about public speaking?

$\begin{array}{ccccc}1 & 2 & 3 & 4 & 5 \\ 1 & 2 & 3 & 4 & 5 \\ 1 & 2 & 3 & 4 & 5 \\ 1 & 2 & 3 & 4 & 5 \\ 1 & 2 & 3 & 4 & 5 \\ 1 & 2 & 3 & 4 & 5 \\ 1 & 2 & 3 & 4 & 5 \\ 1 & 2 & 3 & 4 & 5 \\ 1 & 2 & 3 & 4 & 5 \\ 1 & 2 & 3 & 4 & 5\end{array}$




\section{Appendix H \\ General Food Craving Questionnaire - State}

Please indicate by circling the most appropriate response below, to what extent you agree with each of the statements below right now, at this very moment.

Strongly
Disagree

1. I'm craving tasty food

2. I have an urge for tasty food

3. I have an intense desire to eat something tasty

4. If I ate something, I wouldn't feel so sluggish and lethargic

5. Satisfying my appetite would make me feel less grouchy and irritable

6. I would feel more alert if I could satisfy my appetite

7. If I ate right now, my stomach wouldn't feel as empty

8. I am hungry

9. I feel weak because of not eating

10. My desire to eat something tasty seems overpowering

11. I know I'm going to keep on thinking about tasty food until I actually have it

12. If I had something tasty to eat, I could not stop eating it

13. If I were to eat what I'm desiring, I am sure my mood would improve

14. Eating something tasty would feel wonderful

15. Eating something tasty would make things just perfect

(n)

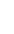

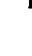

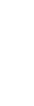

(1)

Strongly

Agree

$\begin{array}{lllll}1 & 2 & 3 & 4 & 5 \\ 1 & 2 & 3 & 4 & 5 \\ 1 & 2 & 3 & 4 & 5\end{array}$

$\begin{array}{lllll}1 & 2 & 3 & 4 & 5\end{array}$

$\begin{array}{lllll}1 & 2 & 3 & 4 & 5\end{array}$

$1 \quad 2 \quad 3 \quad 4 \quad 5$

$\begin{array}{lllll}1 & 2 & 3 & 4 & 5 \\ 1 & 2 & 3 & 4 & 5 \\ 1 & 2 & 3 & 4 & 5\end{array}$




\section{Appendix I \\ Food-Craving Inventory (FCI)}

A craving is defined as an intense desire to consume a particular food (or food type) that is difficult to resist.

At this moment, to what degree are you experiencing a craving for the foods below?

Not at all

1. Fried chicken

2. Sausage

3. Gravy

4. Fried fish

5. Bacon

6. Corn bread

7. Hot dog

8. Steak

9. Brownies

10. Cookies

11. Candy

12. Chocolate

13. Donuts

14. Cake

15. Cinnamon rolls

16. Ice cream

17. Rolls

18. Pancakes or waffles

19. Biscuits

20. Sandwich bread

21. Rice

22. Baked potato

23. Pasta

24. Cereal

25. Hamburger

26. French fries

27. Chips

1

$$
1
$$$$
1
$$

$$
1
$$

1

$$
1
$$

1

1

1

1

1

(

1

1
1

(1)

1

1

1

1

1

1

1
Extremely

12

12

12

12

12

12

12

12

12

12

\section{Somewhat}

45

5 5} 5 5 5 5 5 5 5 5 5 5 5 5 5 5 5 5

12

12

12

2

5


28. Pizza

29. Fruit

30. Garden salad

31. Chicken breast

32. Yogurt

33. Jello

34. Cooked vegetables

35. Popcorn

36. Beans

37. Rice cakes

38. Almonds

$\begin{array}{lllll}1 & 2 & 3 & 4 & 5 \\ 1 & 2 & 3 & 4 & 5 \\ 1 & 2 & 3 & 4 & 5 \\ 1 & 2 & 3 & 4 & 5 \\ 1 & 2 & 3 & 4 & 5 \\ 1 & 2 & 3 & 4 & 5 \\ 1 & 2 & 3 & 4 & 5 \\ 1 & 2 & 3 & 4 & 5 \\ 1 & 2 & 3 & 4 & 5 \\ 1 & 2 & 3 & 4 & 5 \\ 1 & 2 & 3 & 4 & 5\end{array}$




\section{Appendix J}

\section{Dutch Eating Behavior Questionnaire (DEBQ)}

Please read the following items and circle the correct response below.

1. When you have put on weight, do you eat less than you usually do?

2. Do you try to eat less at mealtimes than you would like to eat?

3. How often do you refuse food or drink offered because you are concerned about your weight?

4. Do you watch exactly what you eat?

5. Do you deliberately eat foods that are slimming?

Never Seldom Sometimes Often

1

2

3

Very

Often

0

0

0

1

2

\section{3}

4

6. When you have eaten too much, do you eat less than usual the following day?

7. Do you deliberately eat less in order not to become heavier?

8. How often do you try not to eat between meals because you are watching your weight?

9. How often in the evenings do you try not to eat because you are watching your weight?

10. Do you take into account your weight with what you eat?

11. Do you have the desire to eat when you are irritated?

12. Do you have a desire to eat when you have nothing to do?

13. Do you have a desire to eat when you are depressed or discouraged?

14. Do you have a desire to eat when you are feeling lonely?

15. Do you have a desire to eat when somebody lets you down?

16. Do you have a desire to eat when you are cross? 
Please read the following items and circle the correct response below.

17. Do you have a desire to eat when you are

r
approaching something unpleasant to happen?

18. Do you get the desire to eat when you are anxious, worried or tense?

\begin{tabular}{|c|c|c|c|c|}
\hline Never & Seldom & Sometimes & Often & $\begin{array}{l}\text { Very } \\
\text { Often }\end{array}$ \\
\hline 0 & 1 & 2 & 3 & 4 \\
\hline 0 & 1 & 2 & 3 & 4 \\
\hline 0 & 1 & 2 & 3 & 4 \\
\hline 0 & 1 & 2 & 3 & 4 \\
\hline 0 & 1 & 2 & 3 & 4 \\
\hline 0 & 1 & 2 & 3 & 4 \\
\hline 0 & 1 & 2 & 3 & 4 \\
\hline 0 & 1 & 2 & 3 & 4 \\
\hline 0 & 1 & 2 & 3 & 4 \\
\hline 0 & 1 & 2 & 3 & 4 \\
\hline 0 & 1 & 2 & 3 & 4 \\
\hline 0 & 1 & 2 & 3 & 4 \\
\hline 0 & 1 & 2 & 3 & 4 \\
\hline 0 & 1 & 2 & 3 & 4 \\
\hline 0 & 1 & 2 & 3 & 4 \\
\hline 0 & 1 & 2 & 3 & 4 \\
\hline 0 & 1 & 2 & 3 & 4 \\
\hline
\end{tabular}

19. Do you have a desire to eat when things are going against you or when things have gone wrong?

20. Do you have a desire to eat when you are frightened?

21. Do you have a desire to eat when you are disappointed?

22. Do you have a desire to eat when you are emotionally upset?

23. Do you have a desire to eat when you are bored or restless?

24. If food tastes good to you, do you eat more than usual?

25. If food smells and looks good, do you eat more than usual?

26. If you see or smell something delicious, do you have a desire to eat it?

27. If you have something delicious to eat, do you eat it straight away?

28. If you walk past the baker to you have the desire to buy something delicious?

29. If you walk past a snack-bar or a café, do you have the desire to buy something delicious?

30. If you see others eating, do you also have the desire to eat?

31. Can you resist eating delicious foods?

32. Do you eat more than usual, when you see others eating?

33. When preparing a meal are you inclined to eat something 


\section{Appendix K}

\section{Ruminative Responses Scale (RRS)}

Using the scale provided choose the corresponding numerical representation that best describes your own general attitude and feelings when faced with problems. Please fill in the appropriate number in the space provided next to each question.

1

Almost

Never
2

Sometimes

Often
4

Almost

Always

Please indicate what you generally do, not what you think you should do.

When you encounter problems, you:

1. think about how alone you feel

2. think "I won't be able to do my job if I don't snap out of this."

3. think about your feelings of fatigue and achiness

4. think about how hard it is to concentrate

5. think "What am I doing to deserve this?"

6. think about how passive and unmotivated you feel

7. analyze recent events to try to understand why you are depressed

8. think about how you don't seem to feel anything anymore

9. think "Why can't I get going?"

10. think "Why do I always react this way?"

11. go away by yourself and think about why you feel this way

12. write down what you are thinking and analyze it

13. think about a recent situation, wishing it had gone better

14. think "I won't be able to concentrate if I keep feeling this way."

15. think "Why do I have problems other people don't have?"

16. think "Why can't I handle things better?"

17. think about how sad you feel

18. think about all your shortcomings, failings, faults, mistakes

19. think about how you don't feel up to doing anything

20. analyze your personality to try to understand why you are depressed

21. go someplace alone to think about your feelings 
22. think about how angry you are with yourself

\section{Appendix L \\ Debriefing (Study 1)}

Students face many stressful experiences, in and outside of school, including looking and applying for jobs, and public speaking. Although many people may encounter similar events in daily life, the way they perceive and respond to these events may differ. These differences may be based on the degree of control we feel we have over the event, the long-term consequences it may have for us, the resources we think are available to us, and individual difference factors. These appraisals may, in turn, affect the way we choose to cope with events. Although coping strategies are usually aimed at decreasing the distress we're feeling, some forms of coping we choose, such as eating to make ourselves feel better, may have poor long-term health consequences, especially when we choose to eat foods that are high in carbohydrates and fats. This being said, although some individuals use eating to deal with the negative emotions following stressful situations, this isn't the case for everyone, or all situations. In this regard, it may be important to examine the types of food craved in stressful (vs. control) situations, and the strength of the cravings as they may guide the types and amount of food we eat. Changes in reproductive hormones across the menstrual cycle (e.g., estrogen, progesterone) may also influence mood and cause women to be more reactive to stressors, thus affecting their food cravings and choices. For example, we expect that women in the luteal phase of their menstrual cycles will exhibit stronger cravings than those in the follicular phase. Similarly, increased food cravings and choices in women suffering from premenstrual syndrome (PMS) might also be motivated by the need to improve negative mood.

Although psychological factors play an important role in stress-eating, it's likely that stress hormones and reproductive hormones are also important players. In this study you either prepared for a moderately stressful task (give a speech to an evaluating audience about your employability), or performed a non-stressful word scramble and math task (control). Although participants in the stressor condition did not have to perform the task, anticipation of an evaluative speech has proven to act as a stressor in itself. We are looking to see whether individual differences (e.g., level of eating restraint, emotional and external eating, impulsivity, susceptibility to boredom) influence specific food craving and hormone responses during anticipation. In particular, we will be examining whether those individuals who have high levels of eating restraint, who are prone to emotional and external eating, who are impulsive, and who are prone to boredom will experience greater food cravings following a stressor. Furthermore, we expect that hormone levels will be related to food cravings. More specifically, we expect that higher levels of stress hormones (cortisol and alpha-amylase) will be associated with higher carbohydrate cravings. Finally, from saliva samples, we are determining phases of the menstrual cycle. This may be particularly relevant when looking at food cravings since, as mentioned earlier, we expect women with PMS to experience increased negative affect and increased food cravings during the luteal phase of the menstrual cycle compared to the follicular phase. 


\section{Debriefing (Study 2) \\ Debriefing}

Students face many stressful experiences, in and outside of school, including looking and applying for jobs, and public speaking. Although many people may encounter similar events in daily life, the way they perceive and respond to these events may differ. These differences may be based on the degree of control we feel we have over the event, the long-term consequences it may have for us, the resources we think are available to us, and individual difference factors. These appraisals may, in turn, affect the way we choose to cope with events. Although coping strategies are usually aimed at decreasing the distress we're feeling, some forms of coping we choose, such as eating to make ourselves feel better, may have poor long-term health consequences, especially when we choose to eat foods that are high in carbohydrates and fats. This being said, although some individuals use eating to deal with the negative emotions following stressful situations, this isn't the case for everyone, or all situations. In this regard, it may be important to examine the types of food craved in stressful (vs. control) situations, and the strength of the cravings as they may guide the types and amount of food we eat. It may also be important to examine preferences for certain types of foods, as well as reactions to certain types of foods that we may no even be consciously aware of.

In this study you either prepared for a moderately stressful task (give a speech to an evaluating audience about your employability), or performed a non-stressful word scramble and math task (control). Although participants in the stressor condition did not have to perform the task, anticipation of an evaluative speech has proven to act as a stressor in itself. We are looking to see whether individual differences (e.g., level of eating restraint, emotional and external eating) and the stress reaction influence cravings and implicit reactions towards food (measured in the second part of the study.

In the second part of the study you completed a computer task involving pictures of various types of foods, as well as other pictures, followed by a positive or negative word. Your task was to indicate whether the word was positive or negative by pressing a key as quickly as possible. We are interested in your response times on the keyboard to different pairings of foods with positive or negative words. Your immediate response tells us about your automatic feelings towards different foods. If a food that you really like eating was paired with a positive word, you should be faster to respond than if the same picture was paired with a negative word. In particular, we will be examining whether those individuals who are prone to emotional and eating have faster reaction times for certain types of foods associated with emotional eating (such as high-fat and sweet foods) and we would like to whether being exposed to the stressful task (anticipation of a speech) will affect attitudes towards these types of foods. The other pictures that were presented are used as control pictures and they should evoke either negative, neutral, or positive feelings. We also asked you to report your food preferences and cravings in order to compare them to our implicit measure of attitudes towards foods (the computer task).

Research studies in psychology sometimes have to deceive participants as to the actual purpose of a study. Deception was used in this study when some participants were told 
that they would have to give a speech about their employability (and did not actually have to give the speech), and when all participants were told that the focus of the study was performance under conditions of distraction, when the real focus of the study is regarding eating behaviour and attitudes towards different types of food.

The reason we told some participants that they would have to give a speech when in fact they would not have to, was because we needed to put these participants under (moderately) stressful conditions to see how this would affect their mood, food craving and attitudes towards food, but it was not necessary to put them through the increased stress of actually giving the speech.

The reason why all participants were told that the main purpose of the study was to evaluate student performance under conditions of distraction (rather than eating behaviour), was because people can be sensitive to how they appear to others and themselves and this self-consciousness can distort results. Participants may not behave or react in the same way as they would outside of a research lab if they are aware of what we are studying (in this case eating behaviour and automatic reactions towards food). In the case of this study it was extremely important that participants react in a fast and automatic way on the computer task so that we could get an accurate measure of automatic attitudes towards foods, so it was necessary that you did not know that this is what we were measuring. You will now be given a new consent form which obtains your permission for the researchers to use your data from this study, now that the true nature of the study and the deception used has been explained to you.

We hope this study has provided you with information regarding coping mechanisms in response to stressful events, and particularly eating in response to a stressor. Thank you for participation in our study! 